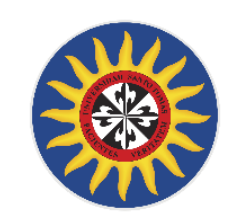

EL CURRÍCULUM DEL ÁREA DE LA EDUCACIÓN FÍSICA COMO PROMOTOR DE HÁBITOS DE VIDA SALUDABLE

DEL COLEGIO PABLO DE TARSO I.E.D.

LOCALIDAD 7a

POR

RAUL DARIO PINZÓN ARCINIEGAS

UNIVERSIDAD SANTO TOMAS

FACULTAD DE CULTURA FISICA, DEPORTE Y RECREACIÓN

Bogotá, Colombia 


\title{
EL CURRÍCULUM DEL ÁREA DE LA EDUCACIÓN FÍSICA COMO PROMOTOR DE HÁBITOS DE VIDA SALUDABLE DEL COLEGIO PABLO DE TARSO I.E.D. LOCALIDAD 7a
}

\author{
POR \\ RAUL DARIO PINZÓN ARCINIEGAS \\ Tesis presentada para optar al título de Magíster en Actividad Física para la Salud
}

Tutor

LUIS ENRIQUE JIMÉNEZ GARZÓN

UNIVERSIDAD SANTO TOMAS

FACULTAD DE CULTURA FISICA, DEPORTE Y RECREACIÓN

Bogotá, Colombia

2017 


\section{AGRADECIMIENTOS}

En primer lugar agradezco a Dios que es el que me da la oportunidad de emprender los proyectos que han hecho de mí un mejor ser humano, a la Universidad Santo Tomas por darme le oportunidad de pertenecer a su proyecto educativo y ofrecerme herramientas que posibiliten ampliar mi formación profesional, a la Secretaria de Educación del distrito por el apoyo recibido para mejorar las condiciones académicas que a su vez potencialicen la labor docente.

Es importante a la vez agradecer, a las personas que han hecho parte hasta hoy de mi proceso educativo y por las cuales he llegado hasta esta etapa, como los es mi abuelita, quien me apoyo siempre que lo necesite para que pudiera a seguir adelante con mis estudios en todas las etapas de mi vida, a mis padres que con su apoyo incondicional y realizando varios esfuerzos estuvieron siempre ahí para mí y en mi más reciente etapa de vida, agradezco a mi esposa quien ha sido de gran apoyo en la realización de muchos de los propósitos que como familia se han adelantado siendo uno la concreción de esta meta y por ultimo a mi Tomas, quien es el aliciente que me levanta todos los días a luchar por mí y para él, siendo mi gran motivación para emprender nuevos proyectos, que sean de ejemplo y orgullo para él. 


\section{CONTENIDO}

AGRADECIMIENTOS

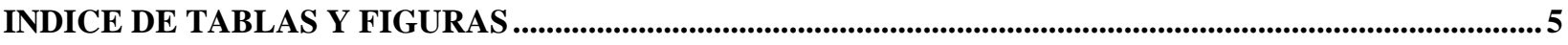

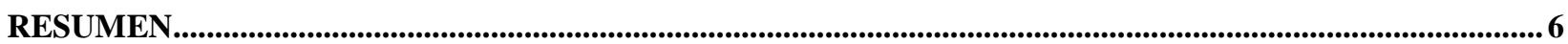

ABSTRACT

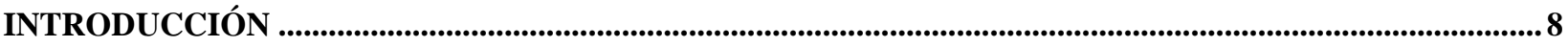

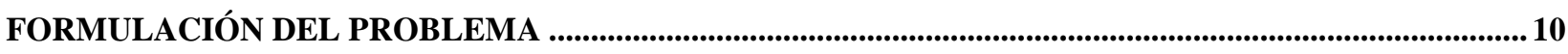

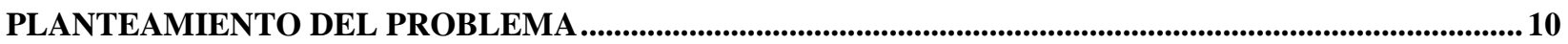

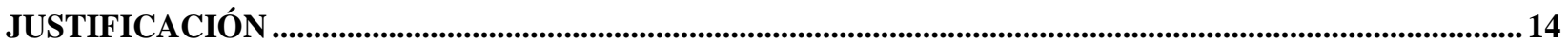

OBJETIVO GENERAL ........................................................................................................................................................ 17

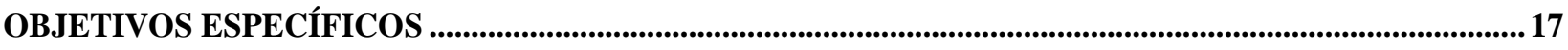

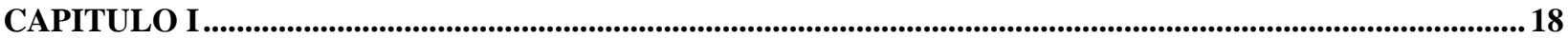

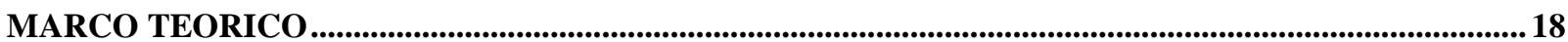

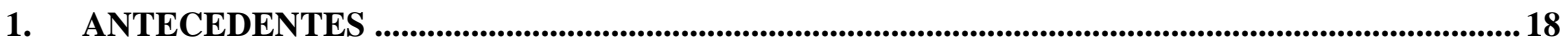

2. HACIA UNA CONCEPTUALIZACIÓN DEL CURRICULO .........................................................22

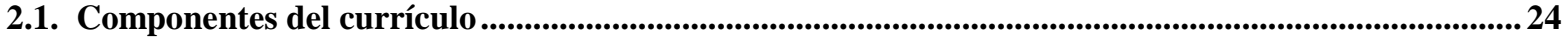

2.2. Enfoques del Currículo ...............................................................................................................................................25

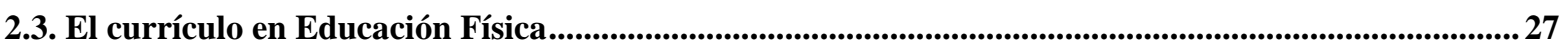

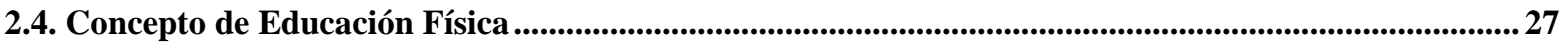

2.5. Cuerpo y Corporeidad. ..........................................................................................................................................30

2.6. Los paradigmas en la enseñanza de la Educación Física ..................................................................................32

3. HABITOS DE VIDA SALUDABLE ......................................................................................................36

3.1 Hacia una conceptualización de Estilo de vida Saludable......................................................................37

3.2 Antecedentes de los programas de Escuelas Saludables ....................................................................................39

3.3 Los programas de Escuelas Saludables como estrategia de promoción ......................................................... 42

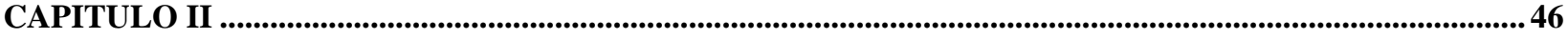

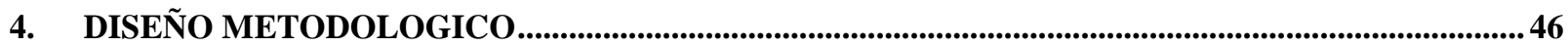

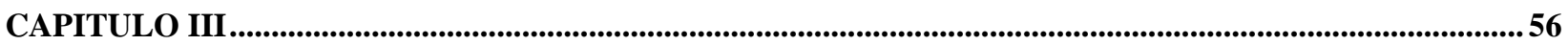

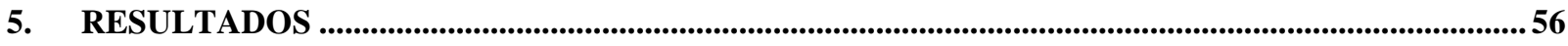

5.1. Documentos Nacionales y Distritales .......................................................................................................................57

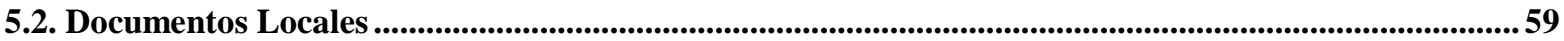

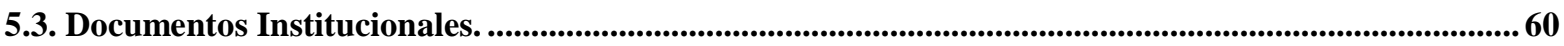

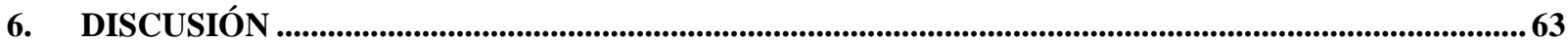

6.1 ¿Porque es importante formar en hábitos de vida saludable? .................................................................64

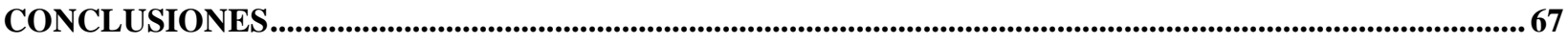

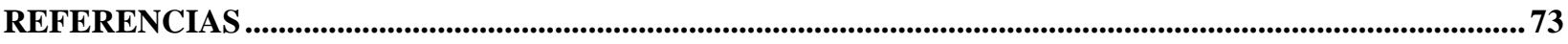

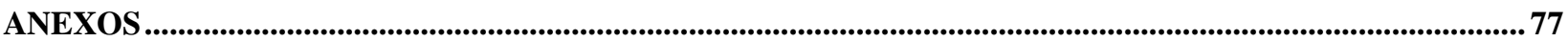




\section{INDICE DE TABLAS Y FIGURAS}

Ilustración 1. El poder regulador del currículo junto a otros inventos. (Sancristan, 2010) ....................... 24

Ilustración 2.Enfoques del Currículo. Elaboración Propia.................................................................... 26

Ilustración 3. Propuesta nuevo paradigma para la enseñanza-aprendizaje de la Educación Física.

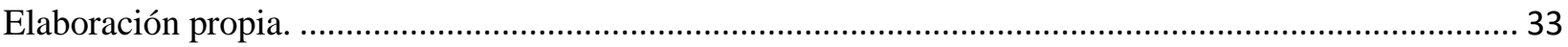

Ilustración 4. Definición de Habitus. Elaboración propia ........................................................................ 38

Ilustración 5. Método hermenéutico. Elaboración propia ........................................................................ 49

Ilustración 6. La imbricación entre los niveles de análisis y el mundo de la vida. (Rodriguez Noguera,

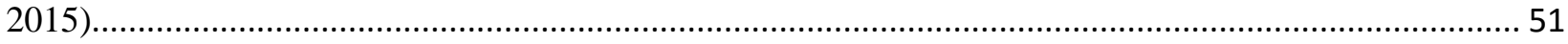

Ilustración 7. Ruta metodológica de investigación. Elaboración Propia ….............................................. 51

Ilustración 8. Triangulación Hermenéutica. Elaboración Propia ........................................................... 54

Ilustración 9. Esquema propuesta preliminar de intervención. Elaboración propia ................................... 72

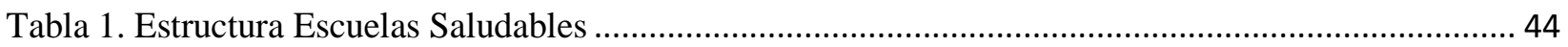

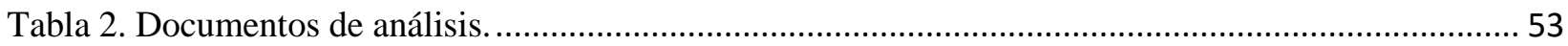

Tabla 3 Matriz de recolección de información de documentos .............................................................. 54

Tabla 4. Matriz de recolección de información por categoría de análisis ............................................... 54 


\title{
RESUMEN
}

El presente documento expone un ejercicio de investigación cualitativo apoyado en el método Hermenéutico para el análisis de documentos nacionales, distritales e institucionales que son parte de la propuesta curricular del área de Educación Física, Recreación y Deportes en el Colegio Pablo de Tarso IED; con el fin de identificar el aporte que esta tiene en la formación de hábitos de vida saludable de los estudiantes. Se llevó a cabo una recopilación de documentos que dan cuenta de las prácticas pedagógicas que se desarrollan en diversos escenarios institucionales e involucran diferentes entidades, las cuales manifiestan interés por el trabajo de la promoción y la prevención de la salud; de esta forma utilizando matrices de recolección y análisis de datos se confronta la información obtenida con el marco teórico que soportan la investigación y los constructos personales producto de la experiencia en la formación disciplinar.

\section{Palabras claves:}

Hábitos de vida saludable, currículo de Educación Física, Promoción y Prevención de la salud

\begin{abstract}
The present document presents a qualitative research exercise supported by the Hermeneutical method for the analysis of national, district and institutional documents that are part of the curricular proposal of the Physical Education, Recreation and Sports area at the "Pablo de Tarso IED" School; in order to identify the contribution that this has in the formation of habits to the student's healthy life. A compilation of documents was carried out that give an account about pedagogical practices that are developed in different institutional contexts and involve different entities, which express interest in the work of the promotion and the prevention of
\end{abstract}


health; In this way using data collection and analysis matrices, the information obtained with the theoretical framework that supports the research and the personal constructs resulting from the experience in the disciplinary formation is confronted.

\section{Key words:}

Healthy living habits, Physical Education curriculum, Health Promotion and Prevent 


\section{INTRODUCCIÓN}

El presente trabajo de investigación se encuentra enmarcado en la propuesta del macro proyecto "El Currículo de Educación Física como promotor de hábitos de vida saludable”, liderado por la Maestría en Actividad Física para la Salud de la facultad de cultura Física, Deporte y Recreación de la Universidad Santo Tomas. El particular del presente documento hace referencia al currículo de Educación Física del Colegio Pablo de Tarso I.E.D. Se desarrolló una investigación de análisis documental de tipo cualitativo que busca confrontar los soportes teóricos relacionados con la formación en hábitos de vida saludables de los estudiantes con las propuestas metodológicas implementadas en el campo de Educación Física, Recreación y Deporte de la institución y los proyectos que se articulan a este.

La metodología de análisis documental se encuentra soportado desde la hermenéutica, la cual permite la recolección de la información, más allá de un ejercicio de análisis gramatical permitiendo al investigador confrontar y tomar posición frente a los resultados de la indagación. Por otra parte, dichos resultados fueron triangulados con un cuerpo teórico referido a las categorías centrales de la investigación permitiendo, identificar el aporte que el currículo hace a la formación en hábitos de vida saludable.

La estructura que se presenta en el documento es:

Un primer capítulo de construcción teórica, que inicia en una elaboración de antecedentes en el cual se observan diversos esfuerzos, reflexiones e indagaciones sobre el tema; seguido de un dialogo de autores referidos a las categorías centrales con los cuales se soportan la identificación de variables a desarrollar en los análisis posteriores. Dicha conceptualización toma referentes de 
orden internacional y nacional que permiten contextualizar la necesidad de revisar dichas temáticas en los espacios escolares.

Un segundo capítulo que da cuenta del diseño metodológico implementado, así como, aportes conceptuales que sustenta el método hermenéutico para el análisis documental, se presenta la construcción y desarrollo de los instrumentos de recolección e interpretación de información.

Un tercer y cuarto capítulo en el cual se presentan los resultados obtenidos en el proceso investigativo, la formulación de una discusión que da cuenta de la triangulación de la información y los alcances de la misma, así como las conclusiones y recomendaciones que sugieren algunas reflexiones y estrategias para la revisión del currículo escolar de Educación Física en la institución educativa distrital Pablo de Tarso. 


\section{FORMULACIÓN DEL PROBLEMA}

¿Cómo el currículo para el área de Educación Física, promueve "hábitos de vida saludable" de los escolares del colegio “PABLO DE TARSO I.E.D.” localidad 7ª de Bogotá D. C.?

\section{PLANTEAMIENTO DEL PROBLEMA}

La formación de los profesionales en educación física, ha estado ligada principalmente a dar respuesta a necesidades del movimiento, entendido este desde su concepción, caracterización y función, convirtiéndose en herramienta para el sector educativo, deportivo, recreativo y separado de alguna manera del campo de la salud.

Dentro del sector educativo la Educación. Física, es presentada dentro de las nueve áreas obligatorias y fundamentales que constituyen el currículo, (Ministerio de Educación Nacional, 1994). A pesar de esto la Educación Física en muchas ocasiones se ve relegada por las demás áreas dándosele menos prioridad al considerar en muchos casos que su componente disciplinar no es fundamental para la formación de los escolares. A la vez se ha creado una mala percepción del profesional de la Educación Física, ya que algunos, desde su práctica profesional desvirtúan la importancia de la asignatura.

Dentro de los planteles educativos el área de Educación Física se ha trabajado en dos grandes campos: "El desarrollo de las capacidades motoras y la ejecución de técnicas deportivas”, esto dado a la formación que reciben los profesionales y que a su vez da respuesta a las necesidades que el contexto socio-cultural demandaba en su momento, dejando de lado otras experiencias enriquecedoras y fundamentalmente aprendizajes significativos en la adquisición de hábitos de vida saludable, que desde su práctica podrían ser de gran importancia para la 
prevención de alteraciones a la salud y de futuras Enfermedades Crónicas No Transmisibles (ECNT).

Es por eso, que se hace necesario realizar una revisión de los documentos nacionales y distritales que se plantean en el sector de la educación para el área de Educación Física y más exactamente, cómo su currículo promueve estrategias idóneas de promoción de vida activa, que contrarresten las consecuencias de la falta de actividad física (sedentarismo), que se presenta en los escolares y que al mismo tiempo sirvan como medio para la adquisición de hábitos de vida saludable.

Dentro del contexto escolar, se percibe desde la cotidianidad un descenso progresivo de la práctica físico-deportiva siendo más relevante en la adolescencia, como consecuencia de los cambios que ha sufrido el estilo de vida de las personas; entre otros factores a causa de la gran demanda y uso de medios electrónicos y tecnológicos que invaden el día a día de los individuos. Al ser esto un efecto latente de los procesos de globalización, "Los estudios científicos que han estudiado la conducta sedentaria en adolescentes en los últimos años han identificado las conductas de ver la tele TV, utilizar el ordenador y el uso de video juegos como aquellas que abarcan la mayor parte de su tiempo, excluyendo las horas que pasan sentados en el horario escolar”. (Valencia Peris, 2013)

La escuela debe brindar los espacios y oportunidades para que los sujetos encuentren otras posibilidades de entretenimiento y esparcimiento que a su vez permitan procesos de formación en hábitos de vida saludables pro pendientes por el mejoramiento de la salud de los jóvenes. Como se ha visibilizado en los últimos planes de gobierno es necesario trabajar por el uso adecuado y asertivo de los nuevos medios tecnológicos pensados como una herramienta para la vida. Por ello 
el área de Educación Física requiere revisar las estrategias para hacerle frente al impacto que este uso masivo ha dejado en las juventudes actuales.

En este sentido; (Vician, Martínez, \& Mayorga, 2015) señalan la escasez de estudios con mediciones objetivas haciendo necesaria la profundización en esta línea de investigación, reconociendo que en la actualidad, la actividad física se asume como variable esencial en la salud de las personas, la cual debe consolidar sus prácticas desde edades tempranas, sin embargo; la tendencia es la inactividad física y la consecuente dificultad en la adquisición de estilos de vida activos en los jóvenes (Vician, Martínez, \& Mayorga, 2015).

Sin embargo, el estudio ENFRENC II ¿Cuánto nos movemos? (Universidad del Rosario, 2007), menciona que el 20,7 \% de los adolescentes son sedentarios, el $50 \%$ irregularmente activos, 19,6 \% regularmente activos y sólo 9,8\% activos; dando cabida a la duda de ¿Cuál es realmente la cantidad y calidad de la actividad física que realizan los adolescentes de nuestro país? El estudio también asevera que las enfermedades crónicas han ido en aumento ocupando el primer lugar como causa de muerte en el país:

"Vale la pena destacar que la proporción de la mortalidad que se atribuye a la hipertensión arterial es de $8,1 \%$, al sedentarismo, de $3,9 \%$ y al consumo de tabaco $3,3 \%$; el $10 \%$ de la población con este problema corresponde a jóvenes”. (Universidad del Rosario, 2007)

También se debe tener en cuenta que, a la falta de actividad física de los niños y adolescentes, se le suman una serie de determinantes, como son, malos hábitos alimenticios, falta de acompañamiento por parte de su núcleo familiar y algunas veces dificultades a nivel emocional. Esto hace que este problema deba estar ligado con un acercamiento de la familia a la escuela para así poder orientar de manera más eficaz programas de prevención que conlleven a 
mejorar los hábitos de vida dentro del entorno en el que interactúan los escolares. Es así como Pérez-López, Sánchez, y Delgado-Fernández (2015) proponen realizar una revisión sistemática de los programas de promoción de la actividad física y alimentación desarrollados con adolescentes, encontrando entre sus resultados el protagonismo de los profesores de educación física en el desarrollo e implementación de estos programas y confirmando el papel relevante de la institución educativa sobre la adquisición y mejora de dichos hábitos desde una perspectiva saludable.

Es por eso, que el papel de la escuela y principalmente el de la Educación Física es de gran relevancia en la construcción de estilos de vida saludables. De esta manera se hace pertinente revisar sistemáticamente como la propuesta curricular del área de Educación Física del colegio “PABLO DE TARSO I.E.D” orienta la formación en hábitos de vida saludables desde su estructura, pues se ha demostrado que la práctica de actividad física y deporte de niños y jóvenes y su estilo de vida está en buena parte condicionado por las oportunidades y experiencias que encuentran en el entorno escolar, especialmente en las clases de educación física y las diferentes opciones extracurriculares que ofrece la escuela. (LLeixa Arribas, González Arevalo, H., Daza, \& Braz, 2015)

Para finalizar y sin emitir verdades absolutas se puede entender que el currículum es la base fundamental de todo proceso pedagógico, que independiente de las posturas de los autores, del como sea visto y entendido por la comunidad educativa, es necesario enfrentarlo, analizarlo, compararlo y ajustarlo para hacerlo más real y aterrizado frente a la realidad que viven los escolares del colegio "PABLO DE TARSO I.E.D” de la localidad 7". 


\section{JUSTIFICACIÓN}

La Educación Física es el área de formación del ser humano que le permite tener contacto con el entorno, es así como la actuación humana en el mundo, mediada por lo corporal, implica ser competente en lo motriz, en procesos de adaptación y transformación; en lo expresivo, en procesos de autocontrol y comunicación; y en lo axiológico, para el cuidado y la preservación de las condiciones vitales del individuo, en concordancia con el entorno social y natural (Ministerio de Educación Nacional, 2010)

La Educación Física vista como promotora de la salud adquiere un valor y un sentido mayor dentro de la comunidad educativa al igual que en nuestra sociedad. Su contribución puede llegar a ser determinante en la generación de hábitos de vida saludables para personas que contribuyan al mejoramiento de la calidad de vida y evite alteraciones en la salud, ligados fundamentalmente en la práctica regular de actividad física, buenos hábitos de alimentación y prácticas sociales sanas.

El sedentarismo y las fallas en los hábitos de vida saludable permiten que diagnósticos como dislipidemias, hipotiroidismo y obesidad evidencian una tendencia al aumento en la población adulta hasta el año 2011, en donde el 1,08\%, el 1,02\% y el 1,01\% de los principales diagnósticos de consulta ambulatoria corresponden a estos tres diagnósticos respectivamente (Integral, Asociación Colombiana de Empresas de Medicina, 2013).

Actualmente en el contexto escolar se viene incrementando la condición del sedentarismo en la población pre-adolescente y adolescente, más específicamente en los jóvenes de $9^{\circ}, 10^{\circ} \mathrm{y}$ $11^{\circ}$ grado, siendo este, una de las principales causas de inactividad física, que a su vez repercuten en un desmejoramiento de la salud de la población escolar. 
Es así como, es importante darle una mirada a los lineamientos que se establecen desde los documentos oficiales del Ministerio de Educación Nacional (MEN) y la Secretaria de Educación del Distrito (SED), en relación con la intensidad horaria de la asignatura de Educación Física, encontrándola limitada a "dos horas" clase por semana en la básica secundaria y en media; en primaria una hora, rol asumido en la mayoría de colegios por profesionales de la educación no especializados en el área.

Por ello es tarea fundamental la revisión y transformación del currículo de Educación Física, del colegio "Pablo de Tarso I.E.D.", en la búsqueda de garantizar que los contenidos, acciones y prácticas educativas, formen en hábitos de vida saludable; los cuales no solo mejoraran la calidad de vida de los estudiantes, sino aportara al mejoramiento de la calidad de vida de las familias y por ende de la sociedad en general.

Por lo cual, la formulación de objetivos y contenidos deben ser correspondientes a la lógica de los contextos sociales; en la medida en que el sujeto requiere poner en práctica sus aprendizajes de manera asertiva, los contenidos trabajados desde el área de Educación Física, articulados con otros saberes y disciplinas proporcionaran elementos claves para el desarrollo de diversas habilidades y destrezas que le permitirán cumplir con las necesidades actuales de sostenibilidad y sustentabilidad; los cuales con urgencia requiere la sociedad y que son unos de los objetivos de la escuela.

Ahora bien, esta tarea implica a su vez revisar y plantear nuevas y mejores estrategias metodológicas de enseñanza y por tanto procesos significativos de evaluación; las transformaciones curriculares deben rescatar la relación saber- contexto de manera que los aprendizajes sean coherentes con las necesidades del medio; si bien los lineamientos dan 
claridad frente a la ruta conceptual de desarrollo para el área, es vital explorar las apuestas metodológicas de implementación que la institución posee en la actualidad.

Las propuestas curriculares escolares no pueden ser vistas como estáticas, se debe comprender que la dinámica de los procesos sociales demanda la flexibilidad y apertura de los procesos enseñanza- aprendizaje. Las sociedades son complejas por su misma configuración, de ahí que requiera que sus componentes estructurales le permitan las transformaciones pertinentes, en pro del mejoramiento de la calidad de vida de las personas y las comunidades.

Y finalmente, a partir de los hallazgos posibilitar nuevas rutas y acciones pedagógicas que conlleven a la promoción de hábitos de vida saludable en pro del mejoramiento de la calidad de vida de los estudiantes de la institución. 


\section{OBJETIVO GENERAL}

Determinar cómo los componentes del currículo para el área de Educación Física en básica secundaria y media, promueven los hábitos de vida saludable en los escolares del colegio Pablo de Tarso I.E.D.

\section{OBJETIVOS ESPECÍFICOS}

- Comparar los documentos curriculares de lineamientos normativos nacionales y distritales, en lo referente a la promoción de hábitos de vida saludable con los documentos institucionales.

- Caracterizar la conceptualización del área de la Educación Física como promotor de hábitos de vida saludable en el ámbito escolar.

- Identificar la pertinencia de los contenidos propuestos en el currículo de Educación Física del Colegio Pablo de Tarso, para la formación de hábitos de vida saludable. 


\section{CAPITULO I}

\section{MARCO TEORICO}

\section{ANTECEDENTES}

Para fines de la presente investigación se realizó una consulta de artículos de revista, libros y tesis de pregrado y posgrado en la búsqueda de documentar diferentes ejercicios investigativos en relación a el currículo del área de Educación Física, la importancia de la actividad física en la escuela y el diseño e implementación de programas acerca de hábitos de vida saludable en el campo educativo.

En nuestro país la mayoría de trabajos investigativos que tienen que ver con el área de Educación Física en el ámbito escolar, se concentran principalmente en resolver problemas a fines con el proceso educativo a nivel general, como lo enmarcan en su investigación (Madrigal Gil \& Urrego Tobón, 2013), donde se muestran cifras muy bajas en cuanto a los trabajos que apuntan a indagar o resolver directamente dificultades que se puedan presentar específicamente en el área de Educación Física. Cabe aclarar que no es que no se tome la Educación Física como medio de intervención en otros contextos fuera de la escuela, pues sí se hace notar dentro de las experiencias sociales de los individuos, pero no de manera directa, entendiendo esto desde la concepción actual de esta área en el contexto escolar, donde se evidencia una necesidad de repensar y revisar sus contenidos para así poder mejorar las prácticas educativas, demostrando experiencias pedagógicas significativas que aseguren una formación integral a los estudiantes, que a si mismo repercutan en una transformación de su realidad personal, social y cultural. 
Es así como, las investigaciones adelantadas han sido abanderadas especialmente en España con la identificación de problemáticas de relación entre la intencionalidad formativa de la educación física y la transformación de hábitos de vida saludable en los jóvenes; (Baena, Cerezo, Delgado, \& Cipriano, julio-diciembre, 2010) plantean que la escuela es la encargada de la promoción de la actividad físico-deportiva, al ser una institución con responsabilidad social por ende delegada de garantizar condiciones que permitan una óptima calidad de vida, de ahí que sea indispensable pensar en diseños curriculares que posibiliten el cumplimiento del objetivo. Se debe tener en cuenta que los docentes que impartan la signatura de Educación Física deben ser personas competentes, dispuestos a ampliar dentro de las instituciones educativas, prácticas de hábitos de vida saludable para los estudiantes, que con ayuda de la influencia de las familias y de sus pares, halla un incremento motivacional de interés por actividades físicamente activas que repercutan en el beneficio de la salud.

De esta manera según (Hellin Gómez, 2003), se generará una cultura dentro de las familias que pertenecen a la comunidad escolar, de la importancia que la actividad física representa en el cuidado de la salud, durante todo el proceso vital de los seres humanos, logrando así, tener personas físicamente educadas, dándole importancia a la Educación Física como promotora de estas experiencias, que dan cuenta del lugar y el reconocimiento que se debe tener con esta área de la educación, para garantizar procesos educativos de calidad que se manejen desde la globalidad.

A su vez y dándole otra mirada a la importancia de la escuela dentro de la dinámica de apropiación de saberes, se puede concebir como un entorno donde se estimule el conocimiento de la salud y la enfermedad, siendo esto una herramienta que estimule la adquisición de hábitos, sentimientos y actitudes favorables para la consecución de una vida saludable, como se refiere en 
los estudios de (Guerrero-Ramos, Jiménez-Torres, \& López-Sánchez, 2014). “Si la educación quiere abarcar a toda la persona y ser integral, la salud no puede quedar fuera de la escuela. Más bien hay que apostar por su tratamiento como una cuestión prioritaria en el currículo que contribuya a formar alumnos sanos, que, con el correr de los años, serán adultos sanos y harán posible una sociedad sana” (Daniel, Jimenez Torres, \& Lopez Sanchez, 2016)

Los estudios de (Madrona, Ricardo, \& Jordán, 2003) refieren la importancia de la Educación Física en la escuela a partir de la percepción de los estudiantes y padres de familia; reconociendo en esta el acercamiento y la relación que tiene con la calidad de vida y la salud, exigiendo que desde su práctica sea más relevante en la contribución del desarrollo personal y prácticas de hábitos de vida saludable. A la vez también se indica que una escuela promotora de la salud es la que basándose en el currículo de Educación Física hace transversal la propuesta, establece un ambiente institucional saludable desde el currículo oculto y adopta relaciones interinstitucionales desarrollando un acompañamiento que sea incluyente para la comunidad educativa. Los resultados de su investigación muestran como los estudiantes y padres de familia consideran útiles los aprendizajes y prácticas que se trabajan desde la asignatura, para su desarrollo físico - corporal y como medio para mantener una imagen corporal adecuada, vinculándolos en su cotidianidad.

Por su parte (Abarca-Sos, Murillo Pardo, Julián Clemente, Zaragoza Casterad, \& Generelo Lanaspa, 2015) evidencian los vacíos conceptuales y metodológicos existentes en los currículos escolares, la importancia de actualización en el diseño de didácticas apropiadas para generar procesos formativos significativos desde la Educación Física. Este estudio revela la falencia en las prácticas de los docentes a cargo del área, las cuales no benefician en nada a la concepción y disfrute de la práctica de actividad física, lo que genera dificultad en la apropiación 
de hábitos de vida saludables. Documenta algunos motivos relacionados con la orientación de la clase y el estilo directivo de los profesores lo que genera menores niveles de competencia en los adolescentes, explicado esto, desde la percepción que cada maestro tiene al momento de liderar la clase de Educación Física, las características de esta, los objetivos trazados dentro del plan de área y el diseño metodológico que se quiera impartir 


\title{
2. HACIA UNA CONCEPTUALIZACIÓN DEL CURRICULO
}

\author{
El profesor mediocre dice. El buen profesor explica. \\ El profesor superior demuestra. El gran profesor inspira.
}

William Ward

El currículo es la carta de navegación de la práctica educativa, él contiene no solo los contenidos programáticos para el momento del aprendizaje, si no también deben dar cuenta de las estrategias, mecanismos y dispositivos utilizados en el ejercicio educativo. Si bien las discusiones en torno al currículo, construcción e implementación son diversas, al responder a tiempos, lugares y procesos distintos; es imperante establecer una aproximación conceptual unificada que sirva de base epistemológica para profundizar acerca de las posibilidades de elaboración de nuevas propuestas curriculares, así como transformación de las vigentes.

Por ello, el currículo debe ser entendido como el producto de procesos históricos, sociales y culturales de las diversas comunidades; si bien pretende objetivar las prácticas educativas estableciendo rutas y delimitaciones; los currículos no pueden desconocer las condiciones del contexto además de las realidades del entorno de las comunidades educativas, (Sancristan, 2010) plantea que:

"El curriculum es un concepto que dentro del discurso acerca de la educación denomina y demarca una realidad existente e importante en los sistemas educativos; un concepto que, si bien es cierto que no acoge bajo su paraguas a toda la realidad de la educación, sí que se ha convertido en uno de los núcleos de significación más densos y extensos para comprenderla en el contexto social, cultural, entender las diversas formas en las que se ha institucionalizado.

No es solo un concepto teórico, útil para explicar ese mundo abarcado, sino que se constituye en una herramienta de regulación de las prácticas pedagógicas" p.11 
Es así como, el currículo direcciona los elementos propios del aprendizaje, clarifica los objetivos y principios de la práctica educativa, por lo tanto, para su asertividad se debe contar con un modelo pedagógico claro, el cual fundamenta las posibilidades del desarrollo de las propuestas curriculares. Ahora bien, es importante reconocer que dichos elementos de construcción necesariamente deben estar articulados a las dinámicas sociales de los contextos; de tal manera que los contenidos sean significativos y respondan a las demandas del entorno, por lo tanto, deben estar construidos desde un componente interdisciplinar que permita relacionar todas las temáticas propuestas en la posibilidad de prácticas que demuestren la validez de los mismos. "La teorización sobre el currículum no puede dejar de ser una construcción progresivamente más interdisciplinar que sirve de núcleo para integrar conocimientos y aportaciones de y en las Ciencias de la Educación" (Sancristan, 2010).

Por ello, la construcción del currículo demanda un desmonte en los paradigmas de la exclusividad del saber; aquellos días donde algunas áreas creían tener superioridad y relevancia en la construcción curricular se abren para integrar y vincular en sus objetivos de aprendizaje los aportes de otras disciplinas que complementan en los educandos la razón de ser del conocimiento.

En concordancia, se debe tener en cuenta que cualquier cosa no puede ser parte del currículo, si bien tendrá presente elementos significativos de los ambientes sociales, deberá regular lo que potencialmente sirve para el objetivo concreto del aprendizaje. Es así como el currículo también regulariza el tránsito de conocimientos y potencia lo asertivo del aprendizaje tal como se muestra en la siguiente figura. 


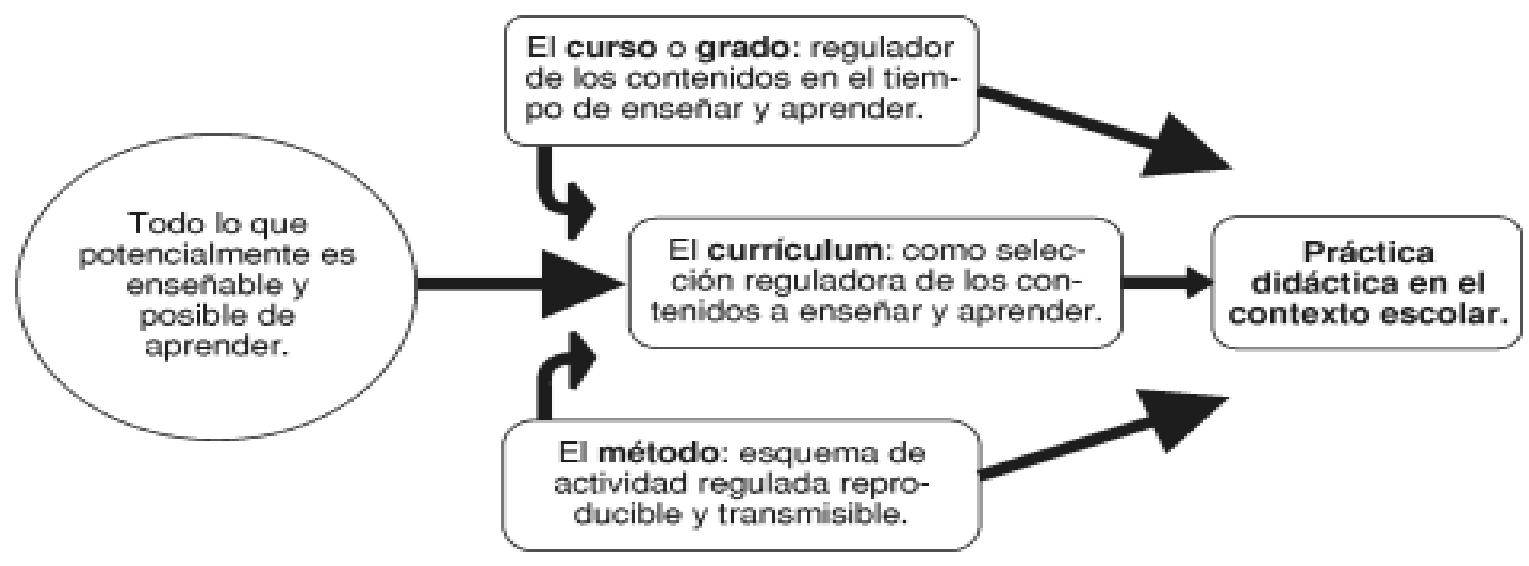

Ilustración 1. El poder regulador del currículo junto a otros inventos. (Sancristan, 2010)

Al tener un ordenamiento del currículo, se regula de manera estricta lo que se enseña y lo que se aprende, se tienen en cuenta los tiempos para estos procesos, se escogen los contenidos acogiendo los que son pertinentes para su composición y teniendo en cuenta otros externos. A la vez se logrará delimitar los territorios de las asignaturas, marcando las diferencias y corresponsabilidad de cada una de ellas dentro del currículo, para así determinar su composición y desarrollo. Todo esto será usado como medio evaluador de la institución escolar, en cuanto a los resultados que regulan las prácticas pedagógicas.

\subsection{Componentes del currículo}

Los currículos escolares requieren para su formulación de 4 pilares fundamentales: objetivos, contenidos, metodología y evaluación; esta estructura garantiza que la propuesta enseñanza aprendizaje este construida desde unas bases claras de fundamentación.

Los objetivos permiten identificar la intencionalidad en la formación, así como los posibles alcances y metas propuestas para resolver el cuestionamiento ¿para que enseñar? De ahí que precisar estos objetivos direccionan claramente el que hacer del docente y la escuela, sin embargo, no se debe reducir a conductas. Las nuevas propuestas convocan a incluir el desarrollo 
de competencias y capacidades que superan lo cognitivo e incluyen el valor por lo procedimental. Por tanto, los contenidos vinculan temas como el saber hacer y el saber ser, lo que implica el desarrollo de habilidades sociales a partir de la propuesta del contenido.

"La intencionalidad de formación constituye el propósito de formación y está en relación con la formación de un estudiante desde lo humano, lo cognitivo y lo práctico, es decir, con las competencias que lo identifican como ser humano, competente y capaz de proyectarse en la sociedad a través de sus prácticas para la comprensión, la reconceptualización y la producción de conocimientos, o la solución de problemáticas”. (Guerra Montoya, 2007, pág. 40)

La propuesta metodológica dará cuenta de las estrategias creadas para el desarrollo del proceso, estas a su vez son de carácter diferencial según la disciplina y el saber especifico, sin embargo, pueden tener momentos de articulación y trabajo cooperativo para el logro de desarrollos cognitivos interdisciplinarios en cumplimiento del objetivo de aprendizaje.

La evaluación como último elemento en la construcción curricular, debe ser entendida como la ruta de verificación del proceso, por lo cual debe tener claridad en cuanto a los criterios y procedimientos a implementar, teniendo en cuenta que no son un producto final si no por el contario unas condiciones observables a lo largo de los diferentes desarrollos.

\subsection{Enfoques del Currículo}

Es importante señalar que la construcción del currículo no se establece desde el mismo paradigma o enfoque este concepto ha tenido transformaciones e incluso sus debates y trabajos teóricos han superado los muros de la escuela, se trasladan a los escenarios sociales y formativos de la comunidad, la familia, las relaciones de vecindad entre otros. Tener claridad acerca de los diversos enfoques del currículo permite identificar la intencionalidad del aprendizaje desde la 
formulación de las herramientas y metodologías de trabajo de los contenidos en el marco de un contexto institucional.

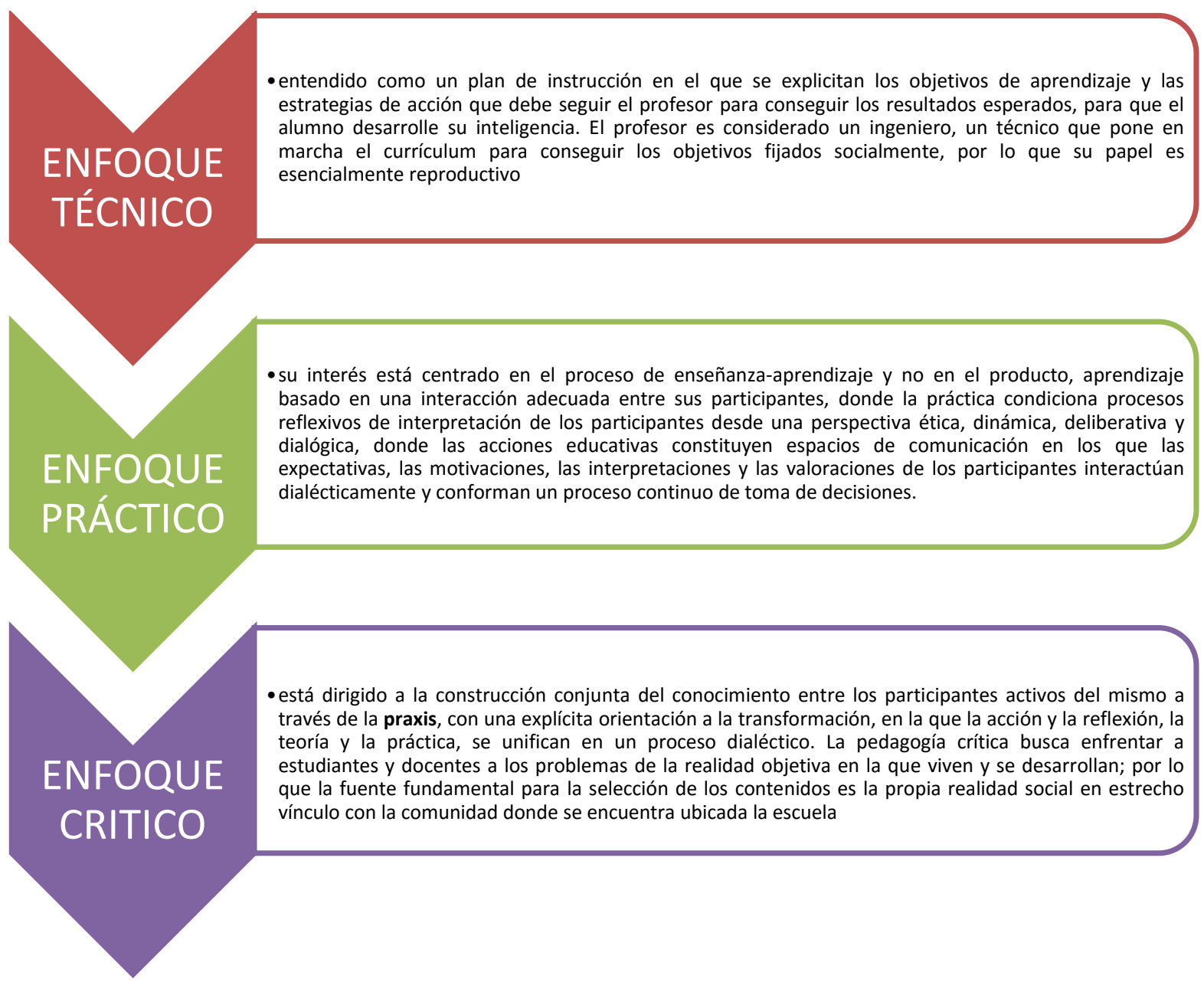

Ilustración 2.Enfoques del Currículo. Elaboración Propia.

Por lo tanto el enfoque que responde a las necesidades de la presente investigación es el que se centra en la persona, es decir el enfoque critico que potencia el desarrollo humano en el cual se fortalecen todos aquellos elementos que son parte axiológica del sujeto y que permiten re-significar el conocimiento y saber disciplinar, es una praxis de los contenidos. (Jimenez Castro, 2008), Cuando los aprendizajes son significativos aportaran a la vida de los estudiantes 
de manera eficaz, al ser útiles en su cotidianidad; esto permitirá acercar la escuela con las realidades sociales de los niños y jóvenes.

\subsection{El currículo en Educación Física}

La Educación Física como saber y disciplina enfoca su objeto de aprendizaje en la corporeidad y todo aquello que su construcción y reconocimiento comprenda, el trasegar de esta disciplina presenta varias evocaciones, que responden a lugares de enunciación diferenciales del saber, lo cierto es que pensar en el objetivo de enseñanza - aprendizaje refiere un vinculación directa con la noción de cuerpo y motricidad; sin embargo dichos conceptos han sufrido en algunos casos de estigmatización desde algunas perspectivas y fueron entregados a los trabajos y aportes exclusivamente del campo de la salud "Desde los albores de la civilización, la actividad física ha traído consigo un acervo de prácticas plagadas de connotaciones místicas, religiosas, laborales y de la lucha, indispensables para sobrevivir en sociedad" (Donet \& Buscà, 2004), es así como re significar la noción de cuerpo y motricidad desde una lógica humanista permea las visión y enfoques metodológicos de la enseñanza de la actividad física.

\subsection{Concepto de Educación Física}

La discusión en relación a el currículo en Educación Física, sus procesos de enseñanza y aprendizaje, requiere definir su objeto de estudio, en la medida en que precisa comprender su que hace específico en el marco educativo. Autores como Bravo Berrocal y Bravo Caro (2008) plantean que la Educación Física supera el tema de lo corporal- físico; se extiende a características de tipo social, es decir el trabajo específico de los contenidos y saberes del área proyecta al desarrollo de habilidades sociales propias de la formación del individuo, por ende de las estructuras sociales. 
Las discusiones actuales entorno a la pedagogía y educación superan la disciplina y se extienden en la formación de seres integrales, con capacidades sociales que le permitan convivir y construir relaciones interpersonales. Los autores plantean "la Educación Física y los Deportes, son un medio magnífico para que el individuo se inicie en sus deberes y derechos sociales, mediante ejercicios colectivos, $\mathrm{y}$, a través de ellos, se incita a poner en práctica ideales de ayuda mutua, esfuerzo común, cooperación, respeto al adversario, etc.” (Bravo Berrocal \& Bravo Caro, 2008).

Ahora bien, es importante reconocer el carácter polisémico de la definición del objeto de estudio de la Educación Física, al ser un saber que atraviesa múltiples disciplinas en su construcción; lo cierto es que tiene un peso importante desde el concepto educativo, es decir, posee un carácter pedagógico indiscutible al afectar los principios básicos de la formación del individuo. Según (Olivera Beltrán, 2006), la definición presenta una dicotomía “como medio y como instrumento en sí mismo" al considerarla una disciplina que puede "educar a través del movimiento" y una "educación del movimiento" el autor define que:

"La actividad física compromete al ser en su totalidad, y aunque su práctica se inscribe en el cuerpo, por el cuerpo y para el desarrollo del cuerpo, ésta presenta dimensiones motrices, intelectuales, cognitivas, expresivas, emocionales, afectivas, relacionales, sociales o espirituales”. Pág. 83

La Educación Física trasciende el escenario educativo, su proyección implica referirse a la disciplina como un estilo de vida, por lo tanto, es considerada desde una mirada humanista y totalmente contextualizada.

Por otra parte, Luis Eduardo Ospina en su artículo acerca del objeto de estudio de la educación física (Ospina, 2007) plantea una discusión relacionada con la confusión que suele 
surgir en el momento de definir el que hacer de esta disciplina; al ser en algunos momentos reducida con expresiones que la condicionan o reducen a prácticas que no trascienden del componente físico. Según el autor al referirse a la Educación Física se debe establecer que:

"Educación Física es una expresión no uní- vacamente entendida, referida a ámbitos de actuación educativa muy diferentes y que ha evolucionado de una manera importante en los últimos años. Una lexía con significados muy distintos en función de: el momento histórico en que se desarrolla; la tradición y el contexto cultural; las escuelas y los métodos utilizados; las ciencias y las teorías que le prestan su apoyo; los diferentes campos de intervención pedagógica; los principios filosóficos, antropológicos, axiológicos, que la fundamentan, etc.” (Cecchini, 1996, 19). En: (Ospina, 2007, pág. 151) Existe un nivel de complejidad en la acción y comprensión del concepto de Educación Física, así como muchas de las estructuras tradicionales en educación requiere que el campo y los docentes desmonte paradigmas conservadores que limitan el accionar de la disciplina, se requiere que el individuo, los docentes, la escuela y la sociedad misma comprendan que el proceso de enseñanzaaprendizaje, así como el desarrollo de capacidades y la actividad física en sí misma, es un componente vital en la formación de los individuos.

Frente a las reflexiones históricas acerca la aparición de la Educación Física en el escenario educativo, en la que se puede deducir un concepto de la disciplina , (Gonzalez Herrera \& Gonzalez Herrera, 2010) precisa que inicialmente la Educación Física en la escuela no fomentaba el conocimiento del cuerpo, si no se reducía a garantizar la salud, canalizar las pasiones humanas y formar el carácter mediante la práctica y la coordinación; posteriormente se incluyó reducir los efectos del sedentarismo. En las últimas décadas las reflexiones en relación a los fundamentos o principios de la Educación Física en la escuela han incluido toda la discusión pedagógica entorno a la creación de condiciones para el desarrollo corporal y motriz de los 
sujetos, abriendo la frontera de la acción y los principios de la disciplina no solo en el campo educativo sino en lo social en general.

\subsection{Cuerpo y Corporeidad.}

El cuerpo humano es la mejor imagen del alma humana.

Ludwig Wittgenstein.

En el cuerpo de cada individuo se vislumbra una historia, este responde a unas condiciones sociales, culturales, políticas y económicas que lo configuran y lo hacen resultante de un proceso, permite evidenciar la complejidad de las relaciones del sujeto con el mundo. El ejercicio de la corporeidad se traduce en lenguaje, la comunicación trasciende los signos y decodificaciones, el hombre es capaz de crear nuevas formas de trasmitir mensajes, diversas maneras de expresarse. El lenguaje corporal es vital en el análisis de las relaciones humanas; hace parte de una lectura de mundo y por ende tiene gran capacidad de transformación. Por ello se hace necesario por un lado criticar, analizar y reflexionar acerca de todas aquellas estrategias, conocimientos y contenidos que vinculen el trabajo con el cuerpo y por otro educar en su reconocimiento, cuidado y preservación.

La noción de cuerpo ha tenido transformaciones ancladas a las particularidades de los momentos históricos ${ }^{1}$, en los cuales el concepto de hombre y por ende cuerpo se transformó según las visiones de mundo de cada momento, es así como en la antigüedad los esfuerzos se concentraban en la explicación del origen del universo y las cosas, de la aparición del hombre, así como el significado de su existencia; lo que involucro discusiones de orden antropológico desde diferentes disciplinas. En particular la actividad física en civilizaciones como la Grecia

\footnotetext{
${ }^{1}$ Los momentos históricos enunciados, son los construidos desde la historia etnocentrista que establece estas unidades de tiempo a partir de diversos hechos e hitos que caracterizan la evolución del hombre y la sociedad.
} 
antigua se relacionaba con la necesidad del trabajo y la formación del cuerpo en respuesta a las exigencias de las guerras, las cuales requerían de hombres fuertes y resistentes. Este referente de cuerpo fue exaltado por las sociedades de aquella época como símbolo de poder y supremacía, se evidencio en actividades como los Juegos Olímpicos donde se reconocía el poderío de un pueblo a través de los atletas y el nivel de competiciones alcanzadas. (Donet \& Buscà, 2004). Esta visión de cuerpo reconoce la importancia de la actividad física y todo lo relacionado al cuidado corporal.

Para la Edad media, las nuevas concepciones de mundo irrumpieron en la noción de cuerpo, el cual fue condicionado a la mirada religiosa, dogmática y vertical, asociada a las premisas de la moral, las cuales respondían al sistema de valores creados para la época, de ahí que todo lo relacionado con el reconocimiento de la corporeidad tuviese que ser oculto y clandestino. Solo hasta la llegada del renacimiento, el teocentrismo que dominaba las esferas sociales con el argumento de la fe sobre la razón comenzó a ser opacado por las nuevas ideas, las cuales empoderaban al hombre y lo convertían en el centro del conocimiento humano.

La modernidad trae consigo un despertar. La corporeidad y el movimiento resurgen en diferentes esferas el arte, la música, la literatura, la ciencia; reconocen nuevamente la importancia del cuerpo como vehículo de conocimiento. Las discusiones entonces se relacionan con los mecanismos de reconocimiento del cuerpo y por ende del movimiento, se concibe el cuerpo como "un conjunto de estructuras orgánicas que le sirven de instrumento a la mente” (Gonzalez Correa \& Helena, 2010), es decir para la época se establece una división entre la ciencia natural y la espiritualidad, el objetivo central es la formación física del cuerpo se requerían hombre fuertes, disciplinados, obedientes que garantizaran el sostenimiento de las estructuras de poder. 


\subsection{Los paradigmas en la enseñanza de la Educación Física}

Durante el siglo XX, surgen nuevos cuestionamientos acerca de la innegable relación entre cuerpo y espíritu lo que desestima los ideales racionales cartesianos y obliga a repensar la noción de corporeidad "En ese momento aparecen nuevas miradas de la educación física. Se plantea una concepción de cuerpo-sujeto y una educación del movimiento, en contraposición a las teorías mecanicistas y biologístas en las que se educa para el movimiento" (Gonzalez Correa \& Helena, 2010). Se supera la mirada organiza del cuerpo dando paso a la nueva categorización de la corporeidad donde la integralidad es parte fundamental de la formación del individuo. Las corrientes filosóficas contemporáneas incluyeron construcciones teóricas sobre cuerpo, movimiento y corporeidad, es el caso de la fenomenología la cual plantea que la experiencia corporal da cuenta de los aspectos sociales, culturales, cognitivos del sujeto.

Estas nuevas concepciones de corporeidad exigen el desmonte de practica educativas ancladas a los postulados tradicionales, mecanicistas y biológicos y abre la puerta al nuevo reconocimiento del cuerpo como construcción social, por ello las prácticas educativas en relación a la enseñanza aprendizaje de la educación física ampliaran su espectro a vincular en el proceso a diversos actores y escenarios los cuales hacen parte de la vida activa de los individuos.(Ilustración 2) Enseñar acerca de la corporeidad requiere revitalizar las prácticas educativas vigentes. 
Objetivo de Aprendizaje

de la Educación Física

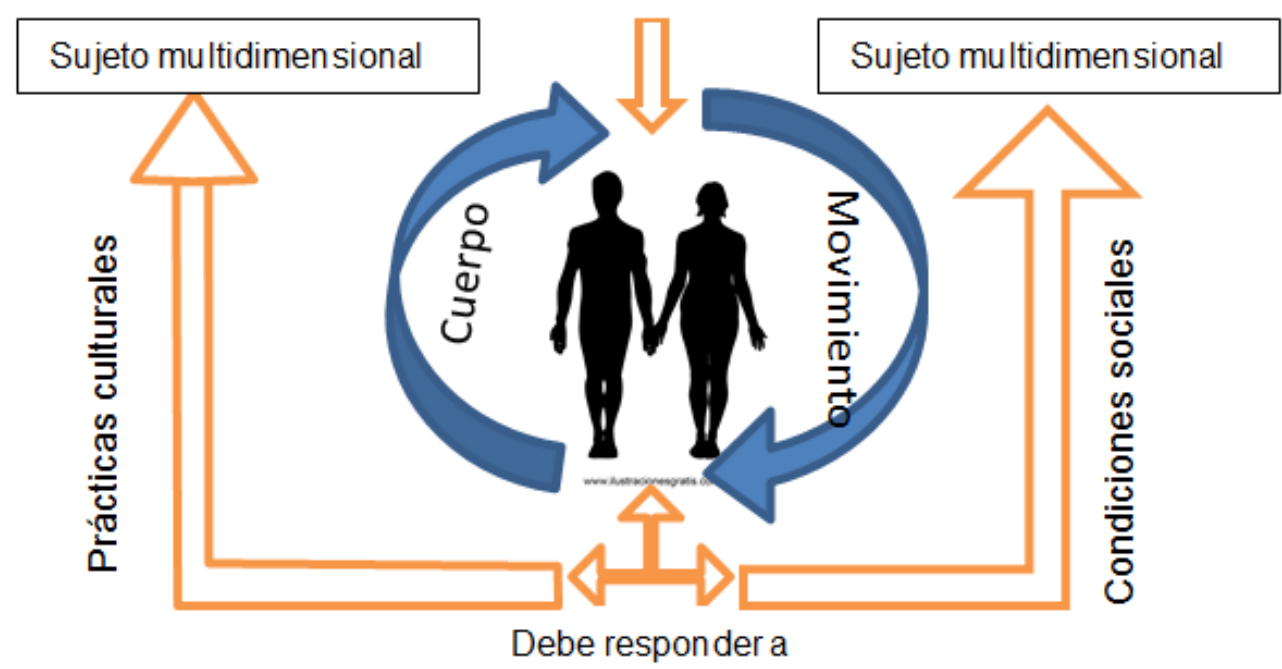

Ilustración 3. Propuesta nuevo paradigma para la enseñanza-aprendizaje de la Educación Física. Elaboración propia.

Por otra parte, como objeto de enseñanza de la educación física se encuentra el movimiento el cual hace parte de la experiencia corporal y es concebido según (Gonzalez Correa \& Helena, 2010) como un cambio de posición y lugar, diferente a motricidad como expresión del ser humano, en ese sentido el cuerpo no es objeto, al contrario, es muestra de la complejidad humana, de ahí que el sujeto se deba analizar desde un carácter multidimensional.

"La motricidad es también creación, espontaneidad, intuición; es manifestación de intencionalidades y personalidades. Cada persona construye su propio movimiento como manifestación de su personalidad. Esta construcción de la identidad motriz resulta de procesos afectivos, cognitivos, estéticos y expresivos que se han adquirido a través de la vida (24). De esta forma, nuestro cuerpo incorpora una técnica determinada que implica también una nueva manera de visualizar el mundo real”. (Gonzalez Correa \& Helena, 2010) p. 176

Por lo tanto, la formación y objetivo de enseñanza de la Educación Física debe permitir vincular múltiples saberes desde la lógica multidimensional, debe acompañar sus contenidos y 
metodologías de aportaciones de otras disciplinas que complementan de manera sustancial el objeto de aprendizaje. El currículo en Educación Física debe recoger las nuevas discusiones y tendencias en materia educativa que existen actualmente, de tal forma que sea coherente con las necesidades pedagógicas actuales.

La enseñanza de la Educación Física ha sufrido transformaciones importantes a lo largo de los años sin embargo solo hasta el siglo XX hará una reflexión juiciosa y sistemática de sus intenciones educativas además de las metodologías desarrolladas; en este sentido (Prieto Rodriguez, Naranjo Polania, \& García Sanchez, 2005) refieren 3 enfoques acerca de la enseñanza de la educación física:

1. Educación físico-deportiva, que se basa en el adiestramiento disciplinado del cuerpo correspondiente a las singularidades anatómicas, fisiológicas y biomecánicas, dando prioridad al rendimiento y la eficacia motriz.

2. Educación psicomotriz, en la que el cuerpo es concebido como una entidad psicosomática la cual se estructura como resultado de las condiciones de maduración y proceso de desarrollo, en el influyen elementos como el medio, además de las características socioculturales de los individuos. De esta manera el cuerpo adquiere significado al ser vehículo de expresión de su contexto.

3. Expresión corporal, en la que se involucran otro tipo de actividades relacionadas con la danza y la gimnasia rítmica que operan como formas de comunicación y nuevos lenguajes, rompen con el Esqueda tradicional de la disciplina y la fuerza, incorpora en la educación física otro tipo de posibilidades de formación corpórea.

Es así como, los cambios en relación al objeto de enseñanza vinculan nuevas formas de la formación del cuerpo que involucran aprendizajes individuales de auto reconocimiento que 
conllevan a sinergias con actores y procesos sociales que aportan al desarrollo cognitivo, además de identificación de características contextuales del sujeto. Todos estos nuevos elementos complejizan la enseñanza aprendizaje del área, pero a su vez posibilitan la exploración de nuevos escenarios y estrategias que aporten a la significación del conocimiento. De ahí que sea tarea imperante la revisión de los currículos escolares, toda vez que estos deben responder a las exigencias de las nuevas dinámicas en relación a la transformación de la escuela y sus procesos.

Como se ha establecido el currículo debe responder en su formulación y estructura de contenidos a la relación conocimiento- contexto, de tal manera que los aprendizajes obtenidos en la escuela incidan asertivamente en los comportamientos y conductas de los sujetos que aprenden, se visibilicen en las acciones propias de la cotidianidad. En este orden de ideas los contenidos propuestos desde el área de educación física deberán recoger en sus formulaciones acciones concretas de transformación del saber y praxis del conocimiento adquirido. 


\section{HABITOS DE VIDA SALUDABLE}

"Nuestros cuerpos son nuestros jardines; nuestras decisiones, nuestros jardineros.”

William Shakespeare

Cuando se habla de hábitos de vida, hablamos de costumbres, que están presentes dentro de las prácticas de habituales de las personas, que están condicionadas por los contextos familiares, sociales, personales, laborales, etc., y por la capacidad de elección que cada uno de los individuos tienen frente a diversas opciones, las cuales pueden repercutir o no en su salud.

Al referirnos específicamente a los hábitos de vida saludables, debemos basarnos en describir como el peso corporal, la actividad física, la adecuada alimentación, la buena higiene personal y un ambiente limpio influye directamente en el bienestar de las personas y en su salud.

Ahora bien, con esto no se quiere decir que este tema es solo competencia de investigación y análisis del sector de la salud, si no convoca a la reflexión en otro tipo de escenarios como la familia, la escuela y la comunidad en general.

La responsabilidad que existe frente al aprendizaje y adopción de hábitos saludables implica un cumulo de factores, que involucran la participación de los diferentes actores que hacen parte de la vida cotidiana de los sujetos; estos aprendizajes se vuelven más significativos y perduran en el tiempo, si se hacen desde los primeros años de vida del individuo, dentro de los contextos socio-culturales en los cuales se encuentren inmersos, como por ejemplo: la familia con la formación en hábitos saludables, pasando por la escuela que fortalece dichas prácticas, que a su vez se visibilizan dentro del grupo social con el cual se sienta identificado.

"La OMS considera que las escuelas son fundamentales para el desarrollo de hábitos de vida saludables y la realización de programas de prevención, al 
reconocer que la edad escolar es un periodo importante para promover y consolidar habilidades en todas las áreas del desarrollo, para reafirmar hábitos de alimentación saludables y para que los niños y las niñas alcancen una excelente calidad de vida y así garanticen las reservas necesarias para cubrir el gasto de energía que demandan las nuevas actividades asumidas durante esta época de la vida" (Fajardo Bonilla \& Angel Arango, 2012. )

En concordancia con lo anterior existe una responsabilidad en la escuela, al ser un escenario clave para el diseño, elaboración e implementación de diversas estrategias que propendan por el fortalecimiento y la promoción de hábitos para una vida saludable, desde el acogimiento de prácticas asociadas, como la actividad física que directamente es aportada por el área de Educación Física.

\subsection{Hacia una conceptualización de Estilo de vida Saludable.}

Al no existir una definición generalizada de estilo de vida, por la diversidad de disciplinas que pueden acoger este concepto desde cada uno de sus saberes y orientarlo de acuerdo a su conceptualización propia, es pertinente de esta forma acoger una de las definiciones más abarcadora, que si bien ha sido criticada por ambigua, amplia y poco operativa, trata de recoger los principales factores que influyen de manera directa en los estilos de vida de los individuos, expresada por la regional de la OMS Europa de este modo:

"Forma general de vida basada en la interacción entre las condiciones de vida en un sentido amplio y los patrones individuales de conducta determinados por factores Socioculturales y características personales” (OMS, 2002, pág. 118)

Ahora bien, al referirnos al término estilo de vida saludable, se debe tener en cuenta diferentes factores que inciden en los comportamientos de las personas, aquellos que impliquen un riesgo para la salud como aquellos que la protegen. Es así como (Elliot \& Deller.S, 1993), en 
sus estudios entiende el concepto de vida saludable como los comportamientos constantes y rigurosos relacionados con la salud que lleva el individuo en procura de una estabilidad física y mental.

Tratando de cimentar un concepto de estilo de vida saludable más renovado y analizando diferentes aportes de autores relevantes en diferentes momentos del siglo XX, (Cockerham, Abel, \& Thomas, 1997) los definen como modelos de conducta colectivos que tienen relación directa con la salud, establecidos en las elecciones personales de cada individuo de acuerdo con sus posibilidades de vida.

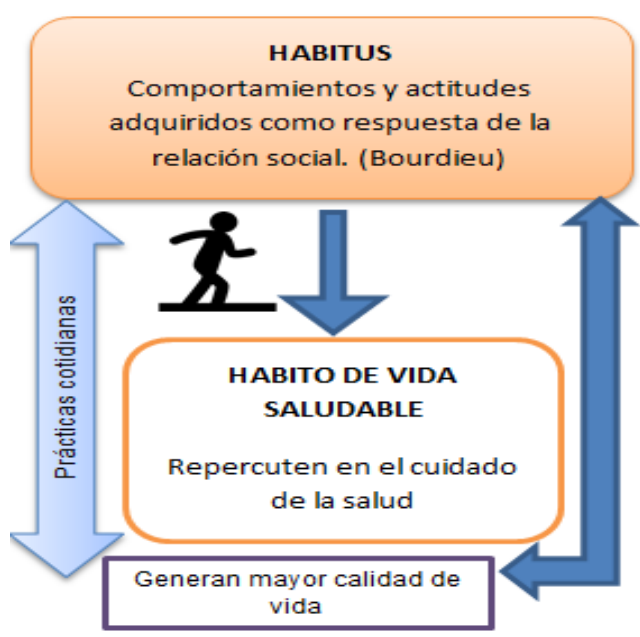

Ilustración 4. Definición de Habitus. Elaboración propia

De ahí, que sea tema de análisis los constructos personales que forman los individuos y que son producto de sus relaciones familiares y el mundo social que posee el sujeto en ocasiones diferencial a la escuela.

Es así como, formar para la consecución de un estilo de vida saludable requiere un compromiso colectivo que inicia en la familia y repercute en todas las instituciones sociales, es deber prioritario de la escuela brindar las herramientas y estrategias pertinentes para dicha fundamentación, ahora bien siendo el hábito una acción que refleja no solo un acto repetitivo, si no da cuenta de los imaginarios y representaciones sociales que los individuos tienen y que 
conforman los sistemas de valores culturales vigentes, su intervención y fortalecimiento debe involucrar permanentemente elementos de contexto.

\subsection{Antecedentes de los programas de Escuelas Saludables}

Los antecedentes de la estrategia de escuela saludable provienen del año 1986 con la conferencia internacional sobre promoción de la salud y la carta de Ottawa, en la cual se afirma que:

"la salud se crea y se vive en el marco de la vida cotidiana; en los centros de enseñanza, de trabajo y de recreo. La salud es el resultado de los cuidados que uno se dispensa a sí mismo y a los demás, de la capacidad de tomar decisiones y controlar la propia vida y de asegurar que la sociedad en que uno vive ofrezca a todos sus miembros la posibilidad de gozar de un buen estado de salud" (OMS, 1996) pág. 10

Este documento pone de manifiesto la necesidad de incorporar en la escuela todo tipo de estrategias para potenciar la promoción de ambientes sanos para el mejoramiento de la calidad de vida de los niños y jóvenes. Así mismo formulo 5 lineamientos estratégicos de implementación:

a. Construcción de políticas públicas saludables

b. Creación de entorno favorable (ambientes físicos, sociales, económicos, políticos y culturales)

c. Fortalecimiento de la participación comunitaria

d. Desarrollo y actitudes personales

e. Reorientación de servicios de salud. (Lamus, Jaimes, Castilla, \& García)

Posteriormente en 1995 la OMS convoco un comité de expertos para formular recomendaciones y lineamientos para el desarrollo de la estrategia, en el caso de los países de América Latina el liderazgo de difusión e implementación de la propuesta estuvo en manos de la 
Organización Panamericana de la Salud (OPS) (Ministerio de la Protección Social; Ministerio de Educación; Ministerio del Medio Ambiente Vivienda y Desarrollo Territorial, 2006)

Esta iniciativa se gesta en la década de los 90 como respuesta a una problemática permanente en relación a las condiciones de calidad de vida de los niños en cuanto a salud y bienestar. Una preocupación permanente de los organismos internacionales se centra en los índices de desarrollo humanos en las diferentes regiones, en la medida en que las discusiones acerca de la sostenibilidad y sustentabilidad de los recursos involucran elementos fundamentales como los niveles de pobreza, alimentación entre otros. De esta manera se sugiere que las organizaciones internacionales y nacionales de diverso orden vinculen a sus agendas temas fundamentales como etilos de vida y calidad de vida en correlación a los grandes temas de salud y educación, por ello estrategias como los programas de escuelas saludables se crean en la búsqueda de vincular todos los actores sociales en la transformación de las condiciones de vida de las poblaciones.

En 1995 la OMS promueve la iniciativa regional de escuelas promotoras de la salud con el objetivo de facilitar la promoción y educación en los temas de desarrollo humano desde una apuesta intersectorial que comprometa a los diversos agentes sociales en la sensibilización y formación para la obtención de mejores condiciones de calidad de vida.

Para Colombia la propuesta se desarrolló a partir de 1996 a apropósito de las apuestas planteadas a la fecha en materia de paz, el país inmerso en un conflicto interno que agudizo la violencia requería de planes que involucraran el tema de la convivencia y la paz desde diversos lugares de enunciación. Los esfuerzos se concentraron en intentar minimizar las brechas económicas existentes y generar herramientas que garantizaran el cumplimiento de los derechos. Para ello programas como escuelas saludables dirigidas desde la política pública aportan de manera significativa a la consecución de los objetivos de paz, es así como, se direcciono la 
implementación a través de los $\mathrm{PEI}^{2}$ institucionales de esta manera se vinculaba la escuela como escenario propicio para la formación de hábitos de vida saludable.

El organismo que impulso inicialmente el desarrollo de la estrategia fue Ministerio de Salud, para 1999 se crea el programa "Escuela saludable, la alegría de vivir en paz" con la alianza estratégica entre el Ministerio de Salud, el Ministerio de Educación Nacional, el ICBF, y la OMS. Es así como, Colombia se convierte en el primer país de la región americana que adopta este programa como política pública lo que genera unas responsabilidades y compromisos de gestión por parte de diversos organismos del sector privado y público, además de una importante asignación presupuestal para el desarrollo del proyecto. En el año 2003 se vinculan a la estrategia los Ministerios de ambiente, vivienda y desarrollo territorial, las Secretarías de Salud de Bogotá y Cundinamarca, el SENA, Acción Social, la Universidad Nacional de Colombia, entre otros, con miras al fortalecimiento de la política.

La constitución de 1991 abrió las posibilidades de desarrollo de múltiples propuestas en el marco de escuelas saludables, al dar paso al trabajo intersectorial y potenciar las herramientas de participación de la ciudadanía en cumplimiento de la categoría de Estado de derecho, por ello normatividades como la ley 100 de 1993 incluyen la formulación de elementos claves para la promoción de la salud y la prevención de enfermedades en toda la población con acciones como el Plan Obligatorio de Salud. En el campo educativo la ley general de educación 115 potencia la creación de espacios y programas conducentes a la promoción y preservación de la salud y la

\footnotetext{
${ }^{2}$ Los Proyectos Educativos Institucionales son la carta de navegación de las instituciones educativas, en él se precisan los objetivos y las metas de formación. Estos proyectos educativos dan cuenta de los modelos, enfoques y estrategias pedagógicas a través de la formulación de los currículos, los cuales deben responder a las lógicas del contexto. Intervenir el currículo debe potenciar un ejercicio de praxis del conocimiento frente a la implementación de este tipo de estrategias como la "Escuela saludable".
} 
higiene, así como la prevención de problemas sociales relevantes, otorga la tarea al área de educación física y deportes para la utilización adecuada del tiempo libre (MEN, 1994).

Para el 2000 se crea la Red Nacional de escuelas saludables con el apoyo de organismos como OPS, OMS, UNICEF, UNESCO, PNUD (programa de naciones unidas para el desarrollo) con el objetivo de concretar un trabajo de cooperación intersectorial que permita el desarrollo integral de la propuesta desde diversos frentes. (Ministerio de la Protección Social; Ministerio de Educación; Ministerio del Medio Ambiente Vivienda y Desarrollo Territorial, 2006)

\subsection{Los programas de Escuelas Saludables como estrategia de promoción}

Esta estrategia es una iniciativa del país proyectada desde los ministerios de Educación y Salud y por el Instituto de Bienestar Familiar. Es una propuesta que sienta sus bases, desde lo que, en el contexto internacional, se menciona como "Las Escuelas Promotoras de Salud", promovidas por la Organización Mundial de la Salud (OMS) y busca la generación de estilos de vida saludable, en un entorno saludable, dentro de una cultura saludable, propiciando el desarrollo del ser humano de manera integral desde el contexto escolar, implicando a toda la comunidad educativa.

De esta forma cuando se habla de la escuela saludable, se debe contemplar como una estrategia de promoción y prevención de la salud dentro del ámbito escolar, donde se cuenta con la interacción de diferentes entes públicos y privados, articulados por los mismos intereses, orientados al mejoramiento de la salud, la calidad de vida y el desarrollo humano de los miembros de las comunidades educativas.

Visto de esta forma, los objetivos claros de esta estrategia proveen por mejorar las condiciones de salud, la calidad de la educación y posibilitar una mejor calidad de vida de los integrantes de la comunidad educativa. Aún de esta manera, no son normativas obligatorias 
estatales, departamentales o municipales, constituir los establecimientos educativos de carácter oficial o privado en "Escuelas Saludables", sino son estos los que a través de sus necesidades adoptan esta clase de estrategias públicas, para la construcción de sus proyectos institucionales de manera voluntaria, adaptando curricularmente todas las áreas del conocimiento, de manera que haya un aporte directo al desarrollo de las dinámicas de enseñanza y aprendizaje de hábitos de vida saludables, cumpliendo de esta forma con los objetivos que se trazan al interior de esta propuesta.

Ahora bien, no se puede desconocer que las instituciones educativas habitualmente contribuyen al desarrollo integral de los niños y jóvenes, desde la práctica docente, encaminando siempre sus experiencias hacia el aprendizaje, no solo de conocimientos, sino también de hábitos que mejoren el bienestar y la calidad de vida de sus estudiantes. De ahí, que la "Escuela Saludable" se reconozca como una estrategia importante en el fortalecimiento de los procesos de prevención y promoción en salud que se imparten de manera esporádica en los contenidos de algunas asignaturas, teniendo una especificidad en el abordaje de su propuesta, a partir de premisas básicas que la fundamentan como las que aparecen a continuación:

$\checkmark$ El derecho a la salud y la educación como derechos fundamentales de la humanidad que el estado debe garantizar.

$\checkmark \quad$ La salud como el resultado de las condiciones de vida del ser humano desde su entorno social y cultural.

$\checkmark$ El reconocimiento de la calidad de vida del ser humano y de cómo una serie de determinantes la deterioran o mejoran, influenciados por diferentes actores sociales que la transforman.

Las instituciones educativas como un agente de reproducción social y un espacio de transformación de las prácticas humanas desde la reflexión, apropiación y aplicación de 
los aprendizajes que generen la movilización y participación activa de la comunidad educativa.

$\checkmark$ La escuela como un contexto habitual de vida, donde se facilita la comprensión de diversos fenómenos individuales, sociales y culturales que favorecen o desfavorecen las condiciones de salud y por ende la calidad de vida.

$\checkmark$ La escuela como un escenario de producción del conocimiento, que posibilite propuestas y proyectos en corresponsabilidad con las dinámicas y necesidades de los contextos. En este orden de ideas la propuesta de "Escuelas Saludables "presenta una serie de componentes y lineamientos que la estructuran, posibilitando la implementación de dicha estrategia en diversos escenarios educativos, como se presentan en el siguiente cuadro:

\begin{tabular}{|c|}
\hline $\begin{array}{l}\text { Componente } 1 \\
\text { Políticas Públicas y Planes para la Escuela Saludable. }\end{array}$ \\
\hline Líneas de Acción \\
\hline $\begin{array}{l}\text { - Articulación de la estrategia Escuela Saludable al PEI, PRAES, PROCEDAS, } \\
\text { POS y Planes de Mejoramiento Institucional. } \\
\text { - Articulación a los PAB. } \\
\text { - Políticas Escolares. }\end{array}$ \\
\hline $\begin{array}{c}\text { Componente } 2 \\
\text { Ambientes Saludables en la Escuela. }\end{array}$ \\
\hline Líneas de Acción \\
\hline $\begin{array}{l}\text { - Ambientes físicos. } \\
\text { - Ambientes psicosociales. }\end{array}$ \\
\hline $\begin{array}{l}\text { Componente } 3 \\
\text { Empoderamiento y participación social en salud. }\end{array}$ \\
\hline Líneas de Acción \\
\hline - Fortalecimiento de las redes de Escuela Saludable. \\
\hline $\begin{array}{c}\text { Componente } 4 \\
\text { Educación para la salud. }\end{array}$ \\
\hline Líneas de Acción \\
\hline $\begin{array}{l}\text { - Fortalecimiento de la capacidad técnica de los actores políticos, institucionales } \\
\text { y comunitarios. } \\
\text { - Fortalecimiento de los conocimientos de salud al escolar. }\end{array}$ \\
\hline $\begin{array}{l}\text { Componente } 5 \\
\text { Reorientación de servicios de salud y vigilancia en salud pública. }\end{array}$ \\
\hline Líneas de Acción \\
\hline $\begin{array}{l}\text { - Servicios escolares de salud, nutrición, y vida activa. } \\
\text { - Articulación entre los planes de beneficios PAB y POSS. }\end{array}$ \\
\hline
\end{tabular}

Tabla 1. Estructura Escuelas Saludables

(Ministerio de la Protección Social; Ministerio de Educación; Ministerio del Medio Ambiente Vivienda y Desarrollo Territorial, 2006) 
Finalmente, esta propuesta sugiere un ejercicio de promoción y prevención en la formación de hábitos de vida saludable desde un escenario educativo, entendiendo las escuelas como los lugares donde los individuos aprenden a partir de diversas técnicas y estrategias a generar procesos cognoscentes acerca del mundo, pero que a su vez entienden como llevarlos a la práctica, dando significado al conocimiento en su diario vivir. 


\section{CAPITULO II}

\section{DISEÑO METODOLOGICO}

La ruta planteada para el presente ejercicio investigativo se centra en la metodología de orden cualitativo, la cual plantea un abordaje del conocimiento a partir de aproximaciones generales de acontecimientos y fenómenos sociales. Esta requiere de un esfuerzo de objetivación que otorgue validez a la recolección y análisis de información. La investigación cualitativa “permite captar el conocimiento, el significado y las interpretaciones que comparten los individuos sobre la realidad social que estudia” Elsy Bonilla. De ahí que la labor del investigador dentro de esta técnica sea demandante, en la medida en que requiere una capacidad analítica y comprensiva, que implique incluso el cambio o transformación en las representaciones mentales del investigador para lograr reconocer las características de los fenómenos y poder llegar a resultados validos de las comprensiones de mundo.

Según (Bonilla Castro \& Rodriguez Sehk, 2000) existen tres momentos claves en la investigación cualitativa:

1. Identificación de la situación problema, lo que implica procesos de exploración y diseño de la ruta a transitar en la indagación.

2. Trabajo de campo con dos finalidades, la recolección de datos cualitativos y la organización de la situación.

3. Identificación de patrones conducentes a plantear las unidades de análisis que permitan la interpretación y contextualización de los fenómenos o situaciones. 
Esta metodología de la investigación requiere unos criterios claros y consecuentes que permitan la validez de la información recolectada, por lo tanto la credibilidad, la consistencia, la fiabilidad y la significancia deberán orientar de manera asertiva la planeación y ejecución de la propuesta (Ramirez Atehortúa \& Zwerg Villegas, Metodología de la investigación: Más que una receta, Enero-Junio 2012) no todos los fenómenos son medibles y no deben ser forzados. El arte de la indagación cualitativa se basa en abstraer aquellos elementos o propiedades no cuantificables del problema, por ello es de vital importancia el diseño de los instrumentos y herramientas de investigación en cumplimiento de los objetivos trazados.

Las técnicas que este tipo de metodología permiten en su proceso de implementación abarcan diversas estrategias como la revisión documental, las técnicas de observación y participación, técnicas de conversación o entrevista, las historias de vida y las de conversación o grupos de discusión (Ramirez Atehortúa \& Zwerg Villegas, Metodología de la investigación: Más que una receta, Enero-Junio 2012). Para los fines propios de la presente investigación se hará uso de la primera técnica.

La técnica de revisión documental debe ser entendida más allá del clásico ejercicio de indagación de textos propio de cualquier labor de investigación; esta estrategia requiere de una interpretación rigurosa de los contenidos, teniendo en cuenta los procesos socio histórico de construcción.

El método a utilizar en la técnica de revisión documental en el marco de la propuesta cualitativa de investigación es la hermenéutica, entendida como el arte de interpretar los textos. Su génesis data de la antigua Grecia con pensadores como Aristóteles con los acercamientos explicativos del mundo y el hombre, pero solo será hasta el renacimiento y la reforma protestante cuando será denominada como una disciplina particular, la cual respondía en su momento 
estrictamente al estudio y análisis de los libros sagrados, así como saberes propios de la lógica y la retórica.

(Morella Arraez \& Moreno de Tovar, 2006) Proponen una distinción en el método, propia de las particularidades de la implementación. Por una parte, señalan un método hermenéutico técnico, referido a la interpretación lingüística y gramatical del texto y una psicológica en la cual se analiza la totalidad del pensamiento del autor desde una postura de contexto. Este método psicológico requiere así mismo precisar algunas características fundamentales para la interpretación:

- El lector de un texto tiene que conocer la psicología y el espíritu del autor para que la comprensión fluya con naturalidad.

- La interpretación debe estar contenida en un horizonte de temporalidad

- Permite el análisis comparativo entre textos y autores

- La explicación no es literal, el intérprete plantea un dialogo con el texto lo que le permite alimentar el análisis final. Schelermacher (2002) citado en (Morella Arraez \& Moreno de Tovar, 2006)

En consonancia con lo anterior el método hermenéutico implementado no refiere en exclusividad a los elementos gramaticales del texto, amplia la interpretación a elementos de contexto nacientes del documento a partir de la posición del autor en un dialogo permanente con la posición y saber del investigador, el cual aporta a la visión de mundo contenida en el lenguaje que Humboldt (1767-1835) propuso como objetivo del análisis hermenéutico y que más adelante Diltthey (1833-1911) complementaria con la necesidad de descubrir el significado de las cosas es 
decir, la interpretación de las palabras asociadas a los fenómenos de contexto. Schaff (1967) citado en: (Morella Arraez \& Moreno de Tovar, 2006)

La hermenéutica posee una naturaleza profundamente humana, puesto que es el ser humano a quien le toca interpretar; necesariamente estarán vinculadas a su ejercicio su lógica de mundo la manera en la que entiende y concibe lo que le rodea, la forma en la que expresa el sentimiento y las condiciones en que se relaciona con los otros.

Por otra parte, la hermenéutica no se preocupa prioritariamente por la intención del autor, toma la acción como vía para la interpretación del contexto social (Ruedas Marrero, Rios Cabrera, \& Nieves, 2009). Lo que implica una aportación de la persona que se encuentra realizando el ejercicio de interpretación, de igual manera reconoce los contextos y necesidades de los ambientes para los cuales se realizan los procesos de análisis.

El método hermenéutico proveniente del paradigma interpretativo tiene 3 etapas principales (Ruedas Marrero, Rios Cabrera, \& Nieves, 2009)

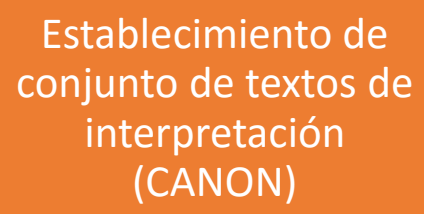

Interpretación de los textos seleccionados
Generación de teorias sobre los numerales 1 y 2

Ilustración 5. Método hermenéutico. Elaboración propia 
Los recursos y herramientas creados para tal fin son definidos por el investigador a partir de los variables y criterios por las cuales su ejercicio de interpretación se desarrollará.

Como parte del método hermenéutico Gadamer (1998) propone la elaboración de un círculo hermenéutico que delimita la forma de la interpretación hermenéutica, al plantear que para su adecuada elaboración se requiere:

“en primer lugar, la disposición del sujeto intérprete a la acción de comunicación, aprestado del componente teórico necesario para desentrañar los significados que el sujeto interpretado, a través del texto, le ofrece, como único elemento de pre - comprensión de su subjetividad. En segundo lugar, la rigurosidad metodológica que el acto de interpretación requiere, adecuando temporalidad y contexto socio-cultural y respetando el formato semántico que exhibe el texto; y, en tercer lugar, la capacidad de discurrir diádicamente en la construcción de discursos en y sobre la pragmática del horizonte que une al hermeneuta, como aplicante y al texto, como situación de faticidad apropiada" (Rodriguez Noguera, 2015)

Ahora bien, en el marco de las posibilidades de elaboración de resultados y estrategia de implementación del método se tendrá en cuenta que se utilizara el análisis sociocultural, es decir supera el análisis formal y semántico y se conduce a una mirada de contexto que profundiza en la relación ser- texto, revisando las condiciones culturales y de contexto en donde se produjeron los textos, lo que permite tener un marco acerca de las dinámicas de pensamiento de los sujetos y las sociedades, así como los elementos propios de los entornos y las realidades culturales de las diversas sociedades objeto de estudio. 


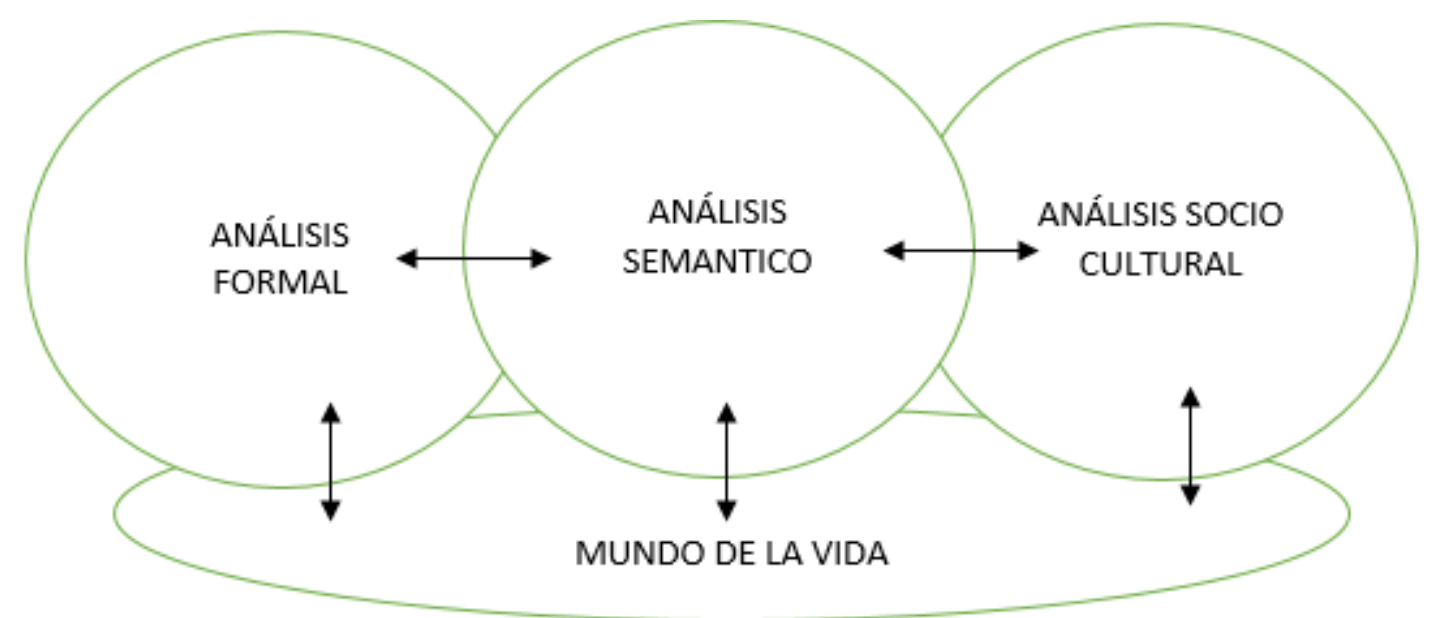

Ilustración 6. La imbricación entre los niveles de análisis y el mundo de la vida. (Rodriguez Noguera, 2015)

El método hermenéutico en su componente de análisis socio cultural permite narrar en el texto la función social en un contexto cultural dado, lo cual es un objetivo propio de la presente investigación, ya que se supera los análisis semánticos de los textos dando paso a una lectura que vincula aspectos sociales propios de los contextos educativos.

A continuación, se presentan las fases del proceso investigativo:
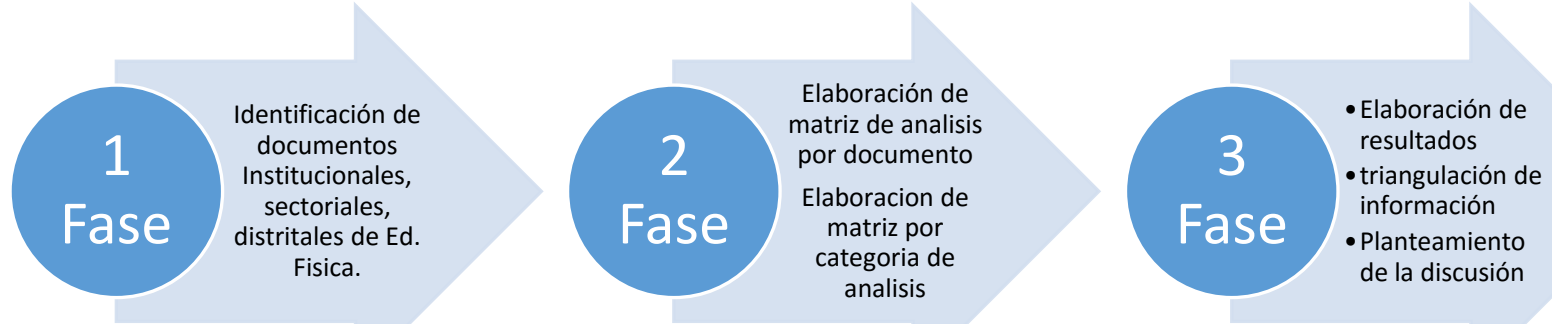

Ilustración 7. Ruta metodológica de investigación. Elaboración Propia 
En cada una de las fases del proceso de investigación se aplicaron instrumentos de recolección de información para los análisis interpretativos y comparativos entre los documentos institucionales, locales y distritales afines al área de Educación Física. Las matrices de análisis dan cuenta de categorías centrales por documento y el establecimiento de unidades de análisis orientadas desde el macro proyecto ${ }^{3}$. Con el fin de identificar las acciones y prácticas tendientes a la formación y promoción de hábitos de vida saludable.

Fase 1. Recopilación de documentos institucionales, sectoriales, distritales relacionados con el área de Educación Física. Se debe precisar que, dentro de los documentos recolectados para fines del ejercicio de indagación, los hallazgos encontrados en la identificación, desestimaron la pertinencia del documento como parte del corpus de la investigación.

Para la definición del corpus de investigación se toman como referencia las orientaciones dadas desde el macro proyecto, en las cuales se solicita la identificación de documentos para cada uno de los niveles en los cuales se puede desarrollar políticas educativas.

Los documentos institucionales revisados dentro de la propuesta investigativa contaron con núcleos temáticos a fines a las categorías relevantes del ejercicio; estos fueron: Proyecto educativo institucional, los planes de área del campo histórico (ética y valores), campo de ciencia y tecnología (ciencias naturales) y el campo de Educación Física, así como los proyectos transversales de orientación sexual, PRAE, Tiempo libre y los proyectos de desarrollo humano de los ciclos III, IV y V.

Con relación a los documentos sectoriales y distritales analizados, se tuvieron en cuenta aquellos que basan su propuesta dentro del marco conceptual de la investigación y son parte del

\footnotetext{
${ }^{3}$ Propuesta de investigación presentada por la Universidad Santo Tomas para el desarrollo de proyectos de grado de la Maestría en actividad física para la salud, en la cual se encuentra vinculado el presente trabajo de investigación.
} 
currículo institucional. Estos son: Enfoque del programa de alimentación escolar, Proyecto Jornada completa (40x40), Proyecto al colegio en bici y Bosa territorio saludable.

En cumplimiento a los objetivos de la investigación, de los documentos revisados solo 5 de ellos responden a las necesidades del análisis hermenéutico

\begin{tabular}{|c|c|}
\hline TIPO DE DOCUMENTO & TITULO \\
\hline Plan de área & $\begin{array}{c}\text { Plan de asignatura de Educación física, } \\
\text { Recreación y deportes }\end{array}$ \\
\hline Proyecto Transversal "Tiempo Libre” & Escuelas de formación deportivas \\
\hline Proyecto Sectorial & Bosa Territorio saludable \\
\hline Proyecto Distrital & Al colegio en bici \\
\hline Proyecto Distrital & Jornada completa: “Orientaciones del Área \\
& $\begin{array}{c}\text { Integradora de Ed. Física, recreación y } \\
\text { deportes para la implementación de la } \\
\text { jornada completa 40x 40" }\end{array}$ \\
\hline
\end{tabular}

Tabla 2. Documentos de análisis.

Fase 2. Elaboración de matriz de análisis por documento, recolección de información por categorías. Se desarrolló una matriz donde se recolecto la información general de identificación de los documentos (tabla 1), que permite evidenciar la fundamentación propia del texto. Así mismo se elaboró una segunda matriz en la cual se consigna las variables propias de la interpretación realizada a cada uno de los textos. Los datos recolectados en cada una de las matrices permitieron los comparativos y triangulaciones propuestos dentro del ejercicio de indagación, realizando un tratamiento individual por título a partir de unas unidades básicas para el análisis documental. 
Tabla 3 Matriz de recolección de información de documentos

\begin{tabular}{|c|c|c|c|c|c|c|}
\hline & \multicolumn{6}{|c|}{ MATRIZ N.O1 RECOLECCIÓN INFORMACIÓN DE DOCUMENTOS } \\
\hline & \multicolumn{6}{|c|}{ COMPONENTES } \\
\hline $\begin{array}{c}\text { DOCUMENTODE } \\
\text { ANALISIS }\end{array}$ & OBJETIYO GENERAL & OBJETIYOS ESPECIFICOS & JUSTIFICACION & $\begin{array}{c}\text { ESTRATEGIA } \\
\text { METODOLOGICA }\end{array}$ & RELACION CON EL P.E.I. & $\begin{array}{l}\text { PROYECCION A LA } \\
\text { COMUNIDAD }\end{array}$ \\
\hline & & & & & & \\
\hline
\end{tabular}

Tabla 4. Matriz de recolección de información por categoría de análisis

\begin{tabular}{|c|c|c|c|c|c|c|c|}
\hline \multicolumn{8}{|c|}{ MATRIZ2. ANALLISI DE DOCUMENTOS } \\
\hline & \multicolumn{7}{|c|}{ UNIDADES DE ANALISIS } \\
\hline DOCUMENTO DE ANALISIS & IDENTFICACION DEL DOCUMENTO & IIPO Y CLASIFICACION DEL DOCUMENTO & \begin{tabular}{|l|} 
ENFOQUEE \\
PEDAGOGICO
\end{tabular} & $\begin{array}{c}\text { CONCEPTO DE EDUCACION } \\
\text { FISICA }\end{array}$ & $\begin{array}{l}\text { CONCEPTOS Y CONTENIDOS } \\
\text { SOBRE ESTILOS DE VIDA } \\
\text { SALUDABLES }\end{array}$ & $\begin{array}{l}\text { ASPECTOS VINCULARES ACERCA } \\
\text { DE LA PROMOCION Y } \\
\text { PREVENCION EN SALUD }\end{array}$ & $\begin{array}{l}\text { ASPECTOS VINCULARES } \\
\text { CON OTROS } \\
\text { DOCUMENTOS }\end{array}$ \\
\hline & & & & & & & \\
\hline
\end{tabular}

Fase 3. Resultados: Luego de recoger la información general de cada uno de los documentos y de haber establecido unas categorías de análisis que dan cuenta a la intencionalidad del ejercicio de investigación, se generan unas conclusiones preliminares en relación a los hallazgos encontrados en la matriz de recolección por categorías, que responde al análisis literal de los documentos. Posteriormente se realizó la triangulación de la información entre los resultados obtenidos de las matrices, el marco teórico y a la argumentación propia del investigador. (Ilustración 3)

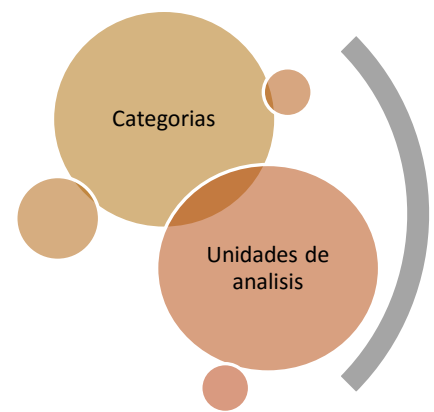

ETAPA I

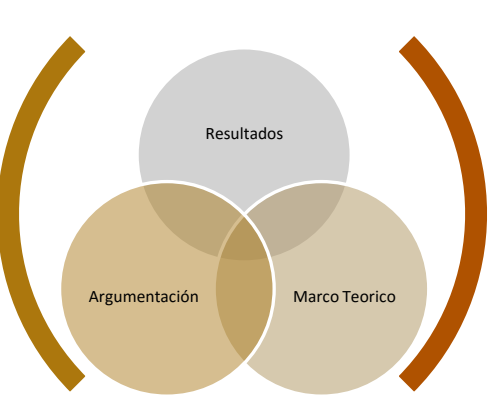

ETAPA II

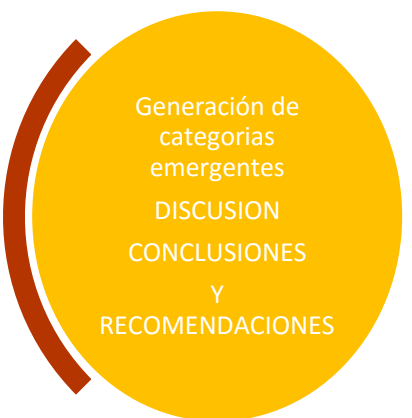

ETAPA III

Ilustración 8. Triangulación Hermenéutica. Elaboración Propia 
Los resultados son insumo para la elaboración de la discusión que contiene las reflexiones de carácter conceptual, a partir de los hallazgos y resultados que la fase anterior arrojo. De esta manera se establecieron las conclusiones y recomendaciones producto de la indagación. 


\section{CAPITULO III}

\section{RESULTADOS}

Teniendo en cuenta la implementación del método hermenéutico a partir de la elaboración del círculo de comprensión, los pasos abordados para la elaboración de los resultados finales de interpretación fueron:

- La comprensión de la información recolectada a través de las matrices de análisis.

- La interpretación de la información teniendo en cuenta una subjetividad razonable del intérprete.

- La aplicación, entendida como la fase de validación de los resultados interpretados, tomando como fundamento la correlación de la información

Entendiendo el desarrollo metodológico en la construcción de los resultados, es importante iniciar la presentación con una contextualización acerca de la pertinencia de este tipo de ejercicio de indagación en el marco de la pedagogía actual.

Las discusiones presentes de orden político, social, económico y cultural en relación al hombre, su bienestar y su entorno, refieren permanentemente al mejoramiento de la calidad de vida por ende temas como los hábitos de vida saludable son parte de los discursos vigentes; la reflexión acerca del ¿Cómo el hombre lleva su vida?, ¿Cómo garantiza su sostenibilidad?; son prioridad de ahí que la familia y la escuela sean los escenarios pertinentes para adelantar los procesos de formación del sujeto, acerca de su responsabilidad con el mismo y con el entorno.

La propuesta metodológica de análisis documental presenta una revisión de los documentos oficiales, de carácter institucional, local, distrital y nacional, que pretenden abordar las categorías de hábitos de vida saludable, promoción y prevención de la salud y conceptualización de la 
Educación Física, como respuesta a las necesidades actuales de hombre en el contexto y su condición de vida.

\subsection{Documentos Nacionales y Distritales}

En relación con los documentos de carácter nacional y distrital, los avances que se muestran desde la conceptualización sobre el objeto de estudio es significativo, al recoger teorías que sustentan la necesidad de fortalecer ciertas prácticas que conllevan a un mejoramiento de la condición del ser humano en cuanto a su calidad de vida, con la generación de recomendaciones y propuestas enmarcadas en los lineamientos internacionales en temas de salud pública y actividad física. De esta manera se infiere que los documentos están soportados desde la normatividad y pretenden crear conciencia acerca de la actividad físicas como medio para la formación en hábitos de vida saludable.

Es el caso del proyecto "jornada completa": Orientaciones del Área Integradora de Educación Física, recreación y deportes para la implementación de la jornada completa ${ }^{4}$, el cual fue elaborado por un grupo de profesionales que son parte de la SED y referencia conceptual y normativamente la necesidad de la ampliación de los tiempos de permanencia en la escuela de los niños, niñas y jóvenes, con el objetivo de incentivar practicas recreo -deportivas haciendo un aporte a la formación de hábitos.

Los documentos responden a políticas gubernamentales, generando estrategias a corto plazo, que soportan necesidades de carácter inmediato en cumplimiento de planes de gobierno como son; presupuestos, condiciones de aplicabilidad, recurso humano y se posibilita su desarrollo si están suscritos en las intenciones y programas de las entidades a cargo (Alcaldía

\footnotetext{
${ }^{4}$ Documento distrital perteneciente al corpus de la investigación, presente en la matriz \#2. Análisis de documentos.
} 
Mayor, Secretaria de Educación Distrital (SED), Instituto Distrital para la Recreación y el Deporte IDRD, Secretaria Distrital de Salud (SDS) y Operadores Privados).

El componente de orden metodológico y operativo es de carácter general, hace referencia a métodos como "El experimental" y el desarrollo "de los aprendizajes esenciales", si bien plantea unas premisas conceptuales básicas como "Las capacidades físicas como los son: la fuerza, velocidad, flexibilidad, coordinación, resistencia serán fortalecidas desde un ámbito recreativo que pretende promover en el estudiante la apropiación de estilos de vida saludable, reconociendo la importancia de la actividad física." (IDRD, 2014) (Ver matriz \#2) sus implementaciones se enmarcan en sesiones prácticas en actividad física sin profundidad en la formación, lo que limita la incidencia del proyecto, convirtiendo su ejecución en algo pragmático sin trascendencia en temas básicos como la apropiación y conciencia de hábitos de vida por parte de los actores participes de los proyectos.

Ahora bien, con relación a las aportaciones de los documentos a los currículos escolares, se establecen unas orientaciones generales de índole teórico para que sean tenidas en cuenta en las instituciones educativas, sin embargo, no se precisa el cómo de dichas implementaciones, en la lógica de las autonomías institucionales; se plantea una transversalización de contenidos en donde manifiestan el desarrollo de experiencias motoras y la especialización deportiva así:

\footnotetext{
${ }^{5}$ Este método es presentado en el documento de "al colegio en Bici” del IDRD. (2014). Propone un ejercicio de aprendizaje significativo a partir del descubrimiento guiado y la resolución de problemas.

${ }^{6}$ Categoría propuesta en la metodología del proyecto de Jornada completa de la SED (2015), que aborda la necesidad de identificación de aprendizajes esenciales para la vida.
} 
Muestra un aporte donde se involucran todos los aspectos del desarrollo motriz cognitivo y social, que serán estimulados desde juegos lúdicos en cada encuentro con los estudiantes, estos darán un valor agregado a su desarrollo físico. ${ }^{7}$

Finalmente, los documentos de orden nacional y distrital reflejan en sus formulaciones un interés en responder a políticas internacionales, por ello sus discursos y metodologías son vinculantes a documentos de carácter oficial que sustentan la necesidad de implementación de dichas propuestas

\subsection{Documentos Locales ${ }^{8}$}

En el contexto local, es notoria la ausencia de proyectos que intervengan en las instituciones educativas, si bien existen programas de recreación, deporte, arte, cultura, etc., los escenarios de aplicación y las comunidades de intervención no se remiten al espacio escolar. Por lo cual el único documento encontrado para fines educativos y que aporta a la propuesta de investigación es "Bosa Territorio Saludable", en su aparte Plan de intervenciones colectivas 2016. Espacio Educativo Secretaria Distrital de Salud; el cual se enfoca estrictamente en un componente de promoción y prevención de la salud, viendo la escuela como un escenario donde confluyen diversos actores de las comunidades.

Es así como dentro del programa establecido en este campo, se pretende el establecimiento de múltiples canales de comunicación, sin evidenciar intervenciones directas con las comunidades, siendo su objetivo principal el que las personas reciba la información para mejorar sus hábitos de vida, así como su salud mental y física. Esta propuesta se enfoca en que la

\footnotetext{
${ }^{7}$ Análisis hermenéutico- interpretativo del documento “al Colegio en Bici” (2014) elaborado en la matriz de análisis \#2.

${ }^{8}$ Para efectos de la investigación la localidad trabajada es la 7 de Bosa en la cual se encuentra el colegio Pablo de Tarso IED. Colegio que refieren los documentos institucionales.
} 
población local conozca las rutas de atención inmediata, los programas de salud ocupacional, física, mental vigentes y que corresponden a las políticas públicas de salud que contempla el plan de desarrollo. Esta estrategia de comunicación se encuentra definida en el documento como el nombre de SINTONIZARTE, la cual pretende un ejercicio de promoción para la detección temprana de enfermedades crónicas no transmisibles.

Si bien la intención de la estrategia se encuentra referida al campo educativo, esta no supera el ejercicio de la promoción a través de la comunicación, es decir la vinculación y articulación del hospital Pablo VI en las instituciones educativas de Bosa no irá más allá de acciones de multiplicación de información.

\subsection{Documentos Institucionales.}

Los documentos institucionales reflejan un gran vacío teórico en cuanto a la conceptualización de las categorías rectoras de esta investigación (Hábitos de vida, enfoque de Educación Física, promoción y prevención en salud); lo que evidencia una ausencia de un soporte pedagógico para las propuesta de implementación contenidas en los planes de estudio, solo remiten a las exigencias de documentos normativos como los lineamientos curriculares de educación física y la ley general de educación de 1994.

Así mismo el proyecto transversal de tiempo libre no cuenta con una fundamentación suficiente y estructurada que valide la metodología, refiere nociones básicas de tiempo libre y recreación. Esto limita la identificación de enfoques, conceptos e intenciones definidas dentro del plan de estudios y el proyecto transversal.

Cabe decir, que si bien estos documentos no están sostenidos por referentes teóricos robustos, que avalen las prácticas y procedimientos enmarcados en los planes de aula para cada 
uno de los grados establecidos dentro de la conformación institucional; se refleja un fuerte interés por el desarrollo humano de los estudiantes, aportando a partir la apropiación de diferentes experiencias motoras una serie de hábitos desde la práctica de la actividad física y el deporte que conllevan a la apropiación de aprendizajes significativos para su formación personal, los cuales generen conciencia y que repercutan en el mejoramiento de la calidad de vida.

Uno de los hallazgos en el documento plan de área del campo de Educación Física y Deportes evidencio una formulación conceptual diferencial para Media en cuanto a la implementación de nuevas estrategias de la enseñanza de la Educación Física. (Ver matriz \#2) en la búsqueda de fortalecer la formación de hábitos de vida saludables para el mejoramiento de la calidad de vida de los jóvenes.

Es evidente, que, si bien se encuentran esos vacíos, se reconocen los esfuerzos en la formulación y estructuración de una propuesta de trabajo a favor de los estudiantes; es necesario construir un discurso pedagógico que sustente la práctica educativa y a la vez clarifique la intencionalidad de la formación.

El documento que referencia el "proyecto de tiempo libre" presenta una falencia en cuanto a la identificación puntual del aporte y el que hacer de otros campos de pensamiento propuestos desde el PEI, toda vez que la transversalidad implica una afectación del currículo institucional y en particular en este caso, el fortalecimiento del currículo de Educación Física, es insuficiente en el planteamiento de estrategias para la promoción y la prevención en salud; este proyecto intenta responder a las necesidades del medio en cuanto al buen uso de los tiempos de ocio; y si bien intenta respaldar su formulación a partir de documentos normativos oficiales como la constitución política, la ley general del deporte, la ley general de la juventud y el manual de 
convivencia del colegio, no presenta un discurso pedagógico correspondiente a la importancia de este tipo de proyectos en la formación integral del individuo.

Los documentos institucionales revisados evidencian unas intenciones positivas por parte de los docentes a cargo de los proyectos es notorio su disposición de trabajar y aportar a la formación de los jóvenes del colegio Pablo de Tarso IED, pero requieren fortalecer y articular el discurso pedagógico de tal manera que sus planes operativos y estratégicos según las edades de desarrollo, articulen la teoría con la práctica de manera asertiva.

La revisión documental permitió reconocer y analizar aportes en cada una de las unidades de análisis que sirven de referente para el cumplimiento de los objetivos trazados en la propuesta de investigación, además de revelar los alcances interpretación que desde lo establecido propicio la implementación método hermenéutico. 


\section{DISCUSIÓN}

La pregunta problema que dio lugar a la presente investigación planteaba la necesidad de revisar y analizar la forma en que el currículo en Educación Física del colegio Pablo de Tarso aportaba a la formación de hábitos de vida saludable, las condiciones pedagógicas en que se desarrollaba la formación, así como las estrategias didácticas y todo tipo de procedimiento a propósito del mejoramiento de la calidad de vida y la salud en los niños, niñas y jóvenes del colegio.

Los hallazgos refieren una debilidad estructural en el currículo. Si bien desde el proyecto educativo institucional se brindan orientaciones generales en relación a enfoque o visión pedagógica, las teorías propuestas en este documento difieren de los contenidos y registros de los planes de estudio y proyectos transversales analizados. El proyecto educativo institucional del Colegio Pablo de Tarso requiere una restructuración profunda, en la medida es que este documento al ser el eje axial de la práctica pedagógica institucional deberá brindar los elementos y herramientas suficientes para la efectiva construcción de un currículo que responda en todas las áreas del saber a las intencionalidades asertiva de educación para la comunidad perteneciente a la institución.

Con respecto al currículo en Educación Física y partiendo de la debilidad del documento PEI, requiere un reajuste en relación a la consolidación del discurso pedagógico en el cual los objetivos de la formación y el aprendizaje deberán develar un aporte a la formación integral del estudiante del colegio Pablo de Tarso. Como se ha expuesto a lo largo del documento y como resultado del análisis, es tarea prioritaria de los docentes del área de Educación Física alimentar el documento curricular del área con los constructos pedagógicos que le brinden solides a las 
propuestas prácticas de intervención y formación, es necesario que los planes de área no solamente den cuenta de los contenidos y el desarrollo de los mismos, sino deberán estar soportados desde las teorías y categorías que se requieren para justificar la necesidad de la formación y para el caso en particular de este ejercicio de indagación la importancia de formar en Hábitos de vida saludable.

\section{1 ¿Porque es importante formar en hábitos de vida saludable?}

Se ha referido a lo largo del documento que el tema de hábitos de vida saludable hace parte de los discursos actuales, frente a la necesidad de establecer mecanismos para la sustentabilidad y la sostenibilidad del medio lo que involucra pensar en los cambios y transformaciones que las poblaciones deben iniciar para garantizar su sostenimiento y permanencia, es decir, la preocupación no solamente gira entorno a el manejo de los recursos, así como las mejores estrategias para su uso; depende igualmente de la manera en que las personas crean mejores condiciones para su calidad de vida. Los ambientes sanos exigen poblaciones responsables de su integridad física y psicológica, por ende, todo tipo de estrategias para mejorar lo que hasta ahora tiene el ser humano requiere de una concientización del autocuidado y su relación con el entorno.

Formar en hábitos de vida saludable trasciende un ejercicio pragmático, lo que implica procesos de desarrollo de pensamiento, en los cuales es necesario que los sujetos comprendan en realidad su importancia y las consecuencias que se generen para su vida. Sin este proceso de significación la acción no incide en cambios sustanciales, las practicas continuaran siendo las mismas en contra del bienestar de la persona. 
Es así como diversas instancias y organismos internacionales se han preocupado por dar a conocer diferentes lineamientos y orientaciones acerca de este tema, al promover una serie de recomendaciones para el mejoramiento de la condición humana, en aspectos tales como la actividad física, la alimentación balanceada, el buen uso del tiempo libre y el manejo asertivo de las emociones. Estas intenciones se reflejan en la formulación de políticas en el campo de la salud las cuales no han trascendido de lo mediático en la sociedad, siendo simplemente divulgadas sin presentar mecanismos de verificación y control.

En este orden de ideas, se puede presentar la escuela como uno de los escenarios prioritarios sobre el cual recae la responsabilidad de la formación en hábitos de vida saludable; reconocer que el ambiente y sus recursos requieren de seres humanos que los utilicen adecuadamente para su bienestar, implica un ejercicio permanente de autocuidado y preservación, de ahí, que los currículos escolares deben insertar en sus finalidades, procesos estrategias y conceptos, referentes que sustenten la importancia de promover hábitos que posibiliten el mejoramiento de la calidad de vida y la salud.

Sin embargo, es imperante señalar dolientes para esta tarea estratégica, ya que debe existir un liderazgo que convoque a todos los saberes y disciplinas a hacer parte de este cumplimiento del objetivo. De esta manera la Educación Física al tener como objeto de estudio el desarrollo de la corporalidad y el que hacer del movimiento, así como el bienestar de la condición física y mental que permite su relación con el entorno; sería la disciplina llamada a liderar dicho proceso, lo que convoca a un trabajo intrapersonal que necesariamente incide en desarrollo humano.

Ahora bien, existen avances significativos en este tema, evidenciados en estudios y propuestas internacionales como el programa "Escuelas saludables” que sugieren la incorporación de conductas generalizadas dentro del ámbito escolar para la formación de hábitos 
de vida saludable, en el caso de Colombia y en específico el distrito capital se intentan acercamientos a este proceso formativo desde diversos frentes estableciendo análisis y reflexiones acerca de la pertinencia de ciertas actividades que promuevan el mejoramiento de la salud y la calidad de vida, las cuales siguen siendo insuficientes frente a la realidad de las comunidades, en la medida que las experiencias presentan análisis argumentativos y teóricos, pero tienen profundas falencias en el componente metodológico que supera el tema de la estructura de trabajo a las condiciones de acción. 


\section{CONCLUSIONES}

A lo largo del proceso de investigación los hallazgos encontrados dan cuenta de la importancia de indagar, reflexionar y discutir acerca de la formación de hábitos de vida saludables en las personas. Al relacionar elementos concernientes al mejoramiento de la calidad de vida en cuanto a la necesidad de concientizar a las sociedades sobre el cuidado de los entornos y del autocuidado, permitirá la conservación de la especie humana.

Los documentos distritales se encuentran construidos con base a los lineamientos internacionales sobre la prevención y promoción de la salud, enfatizando en las recomendaciones propuestas por la Organización Mundial de la Salud (OMS), en cuanto a las prácticas que generan una formación en hábitos de vida saludable; sin embrago al realizar la comparación con los documentos institucionales, se refleja la ausencia de constructos teóricos que validen la formación que proponen los contenidos formulados en los planes de estudio del campo de Educación Física además de un Proyecto Educativo Institucional (PEI), que no cuenta con la incorporación en su formulación de objetivos, metas y estrategias que respondan a la generación de ambientes propicios para el mejoramiento de la calidad de vida.

Ahora bien, con relación al concepto de Educación Física presente en el currículo del campo en el Colegio Pablo de Tarso, no existe una construcción teórica que refiera los elementos categoriales que sustenten las propuestas metodológicas que se presentan, sin embargo la estructura de contenidos da lugar a la identificación de un concepto de la Educación Física que plantea dos pilares, como lo son, el desarrollo de las capacidades físicas a través de un cumulo de experiencias motoras, además de la apropiación de técnicas de los deportes de base y el reconocimiento de la actividad física como generadora de hábitos de vida saludable, referida desde múltiples posibilidades de abordaje para que sea significativo su aprendizaje. 
Los documentos que hacen parte del currículo en Educación Física contemplan dentro de su discurso teórico bases pertinentes para la formación en hábitos de vida saludable, al ser consecuentes con los lineamientos y recomendaciones de entidades internacionales acerca del tema. De este modo se pensaría que la praxis que generan dichas formulaciones van en contra de estrategias significativas y asertivas de implementación, que conlleven a una formación real al responder a las necesidades de los contextos y contar con un nivel apropiación que se refleje en el desarrollo humano de los estudiantes, así como de sus familias.

Finalmente, al ser Licenciado en Educación Física y luego de haber transitado por este proceso de investigación considero importante sustentar el trabajo que se realiza dentro del área con un cumulo de teorías que validen el que hacer docente; así mismo lograr una articulación significativa entre los componentes teóricos y prácticos, que generen trasformaciones en cuanto a la condición de vida de los estudiantes desde las experiencias que ofrece la realización de la actividad física. Así pues, queda demostrado según los resultados obtenidos que es indispensable en la formación integral de los sujetos vivenciar experiencias desde lo corporal que permitan un mejor estado físico y mental, luego que el currículo de Educación Física sea en gran medida el responsable de ofrecer este tipo de conocimiento. 


\section{RECOMENDACIONES}

Dentro de los hallazgos obtenidos, específicamente para la construcción de currículo que promueva y de un aporte significativo a la aprehensión de hábitos de vida saludable y teniendo en cuenta los documentos analizados, que refieren diferentes componentes sectoriales para la construcción del currículo del campo de Educación Física:

- Los aportes de las orientaciones y lineamientos internacionales si bien, precisan la importancia de la reflexión de temas relacionados con el mejoramiento de salud y la calidad de vida de las personas, deberían contextualizar las estrategias de prevención sugeridas, teniendo en cuenta las particularidades culturales de las regiones, toda vez que los procesos políticos y económicos afectan de diversas maneras las condiciones de vida de las comunidades.

- Los proyectos y propuestas de carácter nacional y distrital deberían incluir un componente de evaluación y seguimiento de los alcances e impactos de las estrategias metodológicas sugeridas lo que permitiría reconocer el estado de apropiación y transformación de las comunidades intervenidas, en cuanto a la incorporación de hábitos en la vida cotidiana de las personas. Dando lugar a que dichos procesos generen políticas públicas con capacidad de sostenibilidad, las cuales se arraiguen dentro de las sociedades y por ende creen una transformación social asertiva.

- Si bien los documentos que sustentan los proyectos cuentan con componentes que se pueden articular al currículo escolar, deben profundizar en la relevancia que estos tengan en la formación de los niños, niñas y jóvenes más allá del espacio escolar, es decir, debe 
garantizar una apropiación de hábitos visibles en la formulación y ejecución de su proyecto de vida.

- Es indispensable para la formulación de estrategias que conlleven a la formación en hábitos de vida saludable el diseño y aplicación del proyecto educativo institucional que proporcione orientaciones claras, sustentados en unos elementos pedagógicos conceptuales que apunten a la realidad institucional, con incidencia en la totalidad de prácticas y saberes de las diferentes disciplinas que componen el currículo institucional.

- Con relación al currículo de Educación Física del colegio Pablo de Tarso, es necesario la construcción de la base conceptual para el sustento las propuestas metodológicas y operativas, donde se vea plasmado la intencionalidad de las prácticas que se desarrollan dentro del aula, lo que genera un dialogo entre la teoría y la acción, que evidencie la transformación en las prácticas de vida personal para el mejoramiento de la calidad de vida propia y de su entorno familiar.

\section{PROPUESTA PRELIMINAR DE INTERVENCIÓN CURRICULAR}

Luego de obtener los resultados y consideraciones que se desprenden de la revisión e interpretación de los documentos que hacen parte y nutren el currículo de Educación Física del colegio Pablo de Tarso I.E.D., hay que tener en cuenta dos propuestas de intervención para el mejoramiento del currículo en cuanto a la formación en hábitos de vida saludable en los estudiantes, que garanticen aprendizajes significativos al respecto de este tema y transforme su contexto familiar, escolar, cultural y social:

En primer lugar, como se reflejó en los resultados, el plan de área de Educación Física como documento principal para la planeación, aplicación y evaluación del que hacer del docente del campo, requiere una base teórica que sustente toda la practica pedagógica que en él se muestra, 
ya que no se vislumbra un objetivo claro, un planteamiento académico que lo justifique y unos referentes teóricos que lo respalden lo que metodológicamente se plantea. Es por eso que en este aspecto debo liderar la construcción de dicho fundamento teórico, pues así se fortalecerían las practicas que en este momento se imparten a los estudiantes, encaminadas a resaltar la actividad física como un hábito de vida saludable en todos los grados y en particular en los de la educación media, quienes en la actualidad están referidos a prácticas diferentes de las habituales dentro del plan del campo (ver matriz \#2), queriendo que sean significativas para ellos y puedan trascender a otros escenarios, en los cuales ellos están inmersos dentro de la sociedad para mejorar su calidad de vida.

En segundo lugar y gracias a la formación adquirida durante todo este tiempo de estudio post gradual, me propongo liderar un proyecto inter-disciplinar acerca de la formación en hábitos de vida saludable, que este enmarcado dentro del currículo institucional y sea un referente importante en la composición del proyecto educativo del colegio que se encuentra en construcción y así poder vincular a docentes de otros campos del saber que quieran hacer parte de la formación en este tema desde áreas como lo social, biológico, nutricional, tecnológico, etc.; reuniendo un grupo focal de estudiantes que se sientan parte de las dinámicas que conllevan la formación en hábitos de vida saludable y estén en disposición de cumplir los propósitos que desde el proyecto se programen, llevando a cabo diferentes actividades de intervención no solo para los estudiantes sino también con los demás sujetos que hacen parte de la comunidad educativa. 


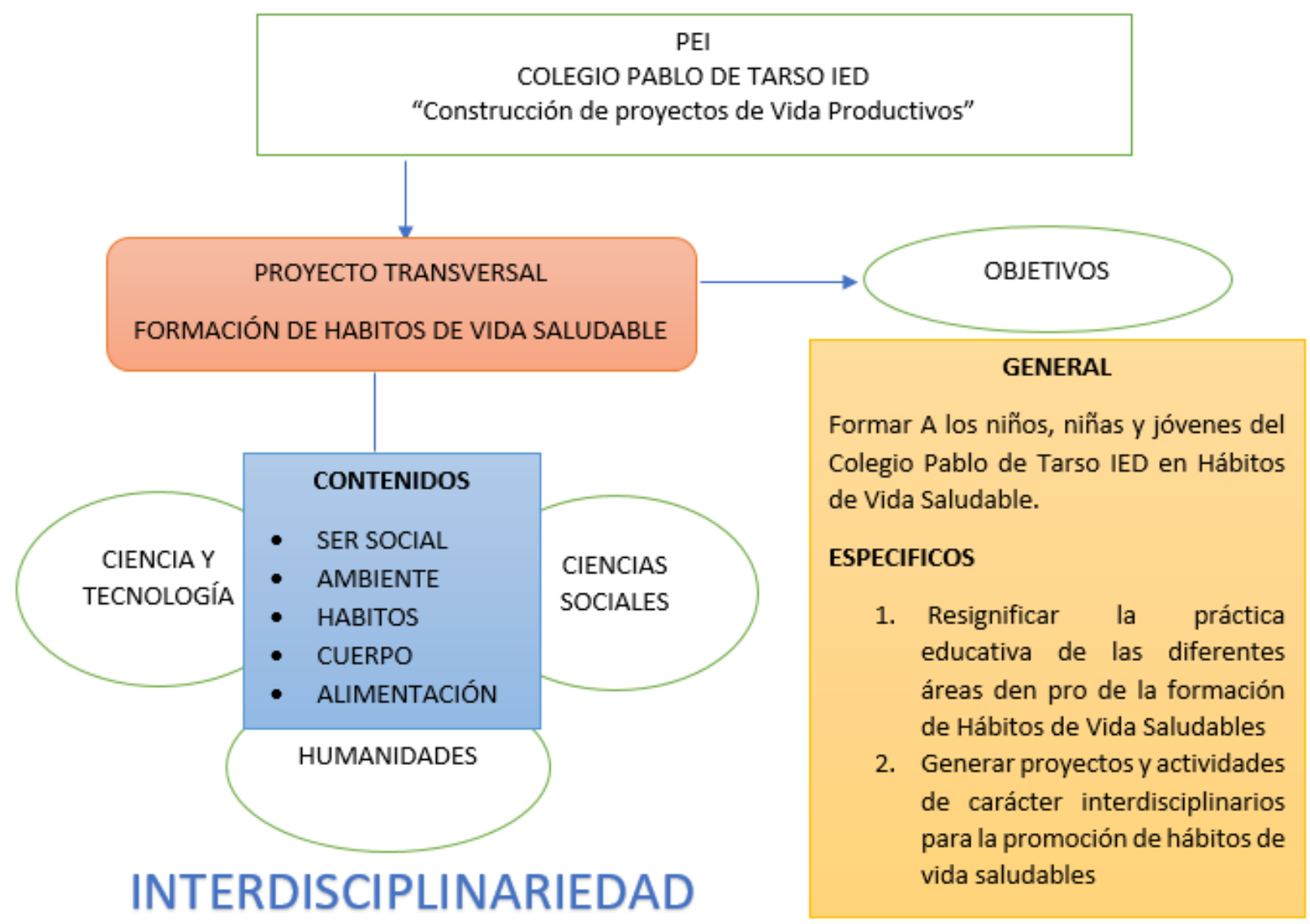

Ilustración 9. Esquema propuesta preliminar de intervención. Elaboración propia 


\section{REFERENCIAS}

Abarca-Sos, A., Murillo Pardo, B., Julián Clemente, J. A., Zaragoza Casterad, J., \& Generelo Lanaspa, E. (2015). La Educación Física: ¿Una oportunidad para la promoción de la actividad física? Retos. Nuevas Tendencias en Educación Física, Deporte y Recreación, núm. 28 Julio-Diciembre, 155-159.

Baena, M., Cerezo, R., Delgado, C. A., \& Cipriano, M. (julio-diciembre, 2010). Factores Que Inciden En La Promoción De La Actividad Físico-Deportiva En La Escuela Desde Una Perspectiva Del Profesorado. Cuadernos de Psicología del Deporte, vol. 10, núm. 2, 57 75.

Bonilla Castro, E., \& Rodriguez Sehk, P. (2000). Más allá del dilema de los métodos . Santafe de Bogotá: Ediciones Uniandes.

Bravo Berrocal, R., \& Bravo Caro, J. A. (2008). LA EDUCACIÓN FÍSICO-DEPORTIVA: UN RETO SOCIAL . Revista Fuentes Vol. 8, 219-229.

Cockerham, Abel, A. R., \& Thomas. (1997). Conceptualizing Contemporary Health Lifestyles: Moving Beyond Weber. En The Sociological Quarterly (págs. 321-342).

Daniel, G. R., Jimenez Torres, M. .., \& Lopez Sanchez, M. (jueves de Febrero de 2016). La Educación Alimentaria y Nutricional. Escuela Saludable versus protectora de la salud. Vol 50 (2), 323-338. Recuperado el 2 de Agosto de 2016, de http://educacionan.blogspot.com.co/2016/02/escuela-saludable-versus-protectora-de.html

Donet, \& Buscà, F. (22 de Diciembre de 2004). Tesis Doctoral. Educación física escolar y transversalidad curricular. Un estudio de casos para el análisis y diseño de tareas motrices significativas. Barcelona: Universidad de Barcelona.

Elliot, \& Deller.S. (1993). Promoting the health of adolescents. New directions for, 119-150.

Fajardo Bonilla, E., \& Angel Arango, L. A. (2012. ). Prevalencia de sobrepeso y obesidad, consumo de alimentos y patrón de actividad física en una poblacion de niños escolares de la ciudad de Bogotá. . Med.Vol 20 Enero-Junio, 103.

Gonzalez Correa, A. M., \& Helena, G. C. (2010). Educación fisica desde la corporeidad y la motricidad. Hacia la promoción de la Salud Vol. 15 N.2. Julio-Diciembre, 173- 187.

Gonzalez Herrera, A. M., \& Gonzalez Herrera, C. H. (2010). Educación Fisica desde la corporeidad y la motricidad. Hacia la promoción de la salud Vol. 15 No. 02, 173-187.

Guerra Montoya, J. W. (2007). Proyecto de Formación de Directivos Docentes en Antioquia. Proceso de diseño curricular. Antoquia, Colombia: SEDUCA - FUNLAM. 
Guerrero-Ramos, D., Jiménez-Torres, M. G., \& López-Sánchez, M. (2014). Escuela saludable versus protectora de la salud (salugénica). Educar Vol.50/2, 323-338.

Hellin Gómez, P. (Febrero de 2003). Hábitos físico-deportivos en la Región de Murcia: implicaciones para la elaboración del currículum en el ciclo formativo de actividades físico-deportivas. Tesisi Doctoral. Murcia, España: Universidad de Murcia.

IDRD. (Febrero de 2014). PEDALEA POR BOGOTA" y"AL COLEGIO EN BIC. Bogotá.

Integral, Asociación Colombiana de Empresas de Medicina. (2013). Cifras e indicadores del Sistema de Salud. BOGOTA,D.C,COLOMBIA.

Jimenez Castro, L. M. (2008). Enfoque curricular centrado en la persona. Revista Educación vol. 32, núm. 1, 63-76.

Lamus, F., Jaimes, C., Castilla, M., \& García, J. G. (s.f.). Hacia una Escuela Saludable. Una experiencia de integración de los agentes entorno a la calidad de vida. Educación y Educadores Vol 6, 17-44.

LLeixa Arribas, T., González Arevalo, C., H., M., Daza, G., \& Braz, V. (2015). ndicadores de calidad para los centros escolares promotores de actividad física y deportiva. Apunts: Educacion Fisica y Deportes, 27-35.

Madrigal Gil, J., \& Urrego Tobón, A. (2013). La Eduación Fisica Renovada desde la investigación educativa. Revista la sallista de investigación Vol.10 No 2, 69-76.

Madrona, P. G., Ricardo, O., \& Jordán, C. (2003). Interés Y Valoración Del Área De Educación Física Por Padres Y Alumnos En La Enseñanza Obligatoria. Revista de Educación, núm. $332,327-355$.

MEN. (1994). Ley 115. ley General de Educacción.

MEN. (1994). Ley General de Educación.

Ministerio de Educación Nacional. (1994). Ley General de Educación. Obtenido de http://www.mineducacion.gov.co/1621/articles-85906_archivo_pdf.pdf

Ministerio de Educación Nacional. (2010). Orientaciones pedagógicas para la educación física, recreación y deporte: Documeto No. 15. Bogotá: MEN.

Ministerio de la Protección Social; Ministerio de Educación; Ministerio del Medio Ambiente Vivienda y Desarrollo Territorial. (2006). Lineamientos Nacionales para la Aplicación y el Desarrollo de las Estrategias de Entornos Saludables. Bogota: Nuevas Ediciones Ltda. 
Morella Arraez, J. C., \& Moreno de Tovar, L. (2006). La Hermeneutica: una actividad interpretativa. Sapiens. Revista universitaria de investigación Año 7. Numero 2. Diciembre, 171-181.

Olivera Beltrán, J. (2006). Perspectivas de la Educación Física en los Albores del Siglo XXI. Apunts. Educacion Fisica y Deportes, 83.

OMS. (1996). Iniciativa Mundial de Salud Escolar.

OMS. (2002). Organizacion Mundial de la Salud. Obtenido de Informe sobre la salud en el mundo: www.who.int/whr/2002/es/index.html

Ospina, L. E. (2007). Sobre el objeto de conocimiento de la Eduación Fisica. Educación y Educadores Vol. 10 num 2, 149-161.

Pérez-López, I. J., Sánchez, P. T., \& Delgado-Fernández, M. (2015). Efectos de los programas escolares de promoción de actividad física y alimentación en adolescentes españoles: revisión sistemática. Nutricion Hospitalaria, 534-544.

Prieto Rodriguez, A., Naranjo Polania, S. P., \& García Sanchez, L. (2005). Cuerpo Movimiento Perspectivas. Bogotá: Centro editorial Universidad del Rosario.

Ramirez Atehortúa, F. H., \& Zwerg Villegas, A. M. (2012). Metodología de la investigación: Más que una receta. AD-minister. Universidad EAFIT Número 20, 91-111.

Ramirez Atehortúa, F. H., \& Zwerg Villegas, A. M. (Enero-Junio 2012). Metodología de la investigación: Más que una receta. AD-minister. Universidad EAFIT Número 20, 91-111.

Rodriguez Noguera, Y. (2015). LA HERMENÉUTICA APLICADA A LA INTERPRETACIÓN DEL TEXTO. EL USO DE LA TÉCNICA DEL ANÁLISIS DE CONTENIDO . Ciencias de la Educación Vol 25 Num 46. Julio-Diciembre, 1-8.

Ruedas Marrero, M., Rios Cabrera, M. M., \& Nieves, F. (2009). Hermeneutica: La Roca que rompe el espejo. Investigación y postgrado Vol 24 N.2, 181-201.

Sancristan, J. G. (Junio de 2010). Scielo. Mexico. Recuperado el 13 de Mayo de 2016, de ¿Qué significa el curriculo?:

http://www.scielo.org.mx/scielo.php?script=sci_arttext\&pid=S1665109X2010000100009\&lng=es\&tlng=es.

Universidad del Rosario. (2007). ¿Cuanto nos movemos? Obtenido de http://www.urosario.edu.co/Universidad-Ciencia-Desarrollo/ur/FasciculosAnteriores/Tomo-II-2007/Fasciculo-7/ur/Cuanto-nos-movemos/ 
Valencia Peris, A. (Febrero de 2013). Actividad Fisica y uso Sedentario de medios tecnologicos de pantalla en adolescentes. Tesis doctoral. Valencia.

Vician, J., Martínez, A., \& Mayorga, D. (2015). Contribución de la educación física a las recomendaciones diarias de actividad física en adolescentes. Nutrición Hospitalaria: Departamento de Educación Física, Universidad de Granada, 1246 -1252. 
ANEXOS

\begin{tabular}{|c|c|c|c|c|c|c|}
\hline \multirow[b]{3}{*}{ DOCUMENTO DE ANALISIS } & \multicolumn{6}{|c|}{ MATRIZ N.01 RECOLECCIÓN INFORMACIÓN DE DOCUMENTOS } \\
\hline & \multicolumn{6}{|c|}{ COMPONENTES } \\
\hline & OBJETIVO GENERAL & OBJETIVOS ESPECIFICOS & JUSTIFICACION & ESTRATEGIA METODOLOGICA & RELACION CON EL P.E.I. & PROYECCION A LA COMUNIDAD \\
\hline $\begin{array}{c}\text { Plan de Área EDUCACION } \\
\text { FISICA Colegio Pablo de } \\
\text { Tarso IED }\end{array}$ & No Presenta & No presenta & No presenta & $\begin{array}{l}\text { Núcleos temáticos, distribuidos en } \\
\text { cuatro periodos académicos que } \\
\text { responden a las habilidades y } \\
\text { capacidades motrices de los niños } \\
\text { y jovenes, situados en las etapas } \\
\text { de desarrollo. } \\
\end{array}$ & \begin{tabular}{|l} 
Direcciona los procesos \\
académicos del campo de \\
educación física, recreación y \\
deporte, teniendo como base el \\
entoque pedagógico del colegio, el \\
sistema de evaluación y la \\
organización institucional por \\
ciclos. Apunta propósito del PEI \\
desde la intencionalidad de los \\
contenidos en el ultimo ciclo de \\
enseñanzza.
\end{tabular} & No presenta \\
\hline $\begin{array}{l}\text { PROYECTO "ESCUELAS } \\
\text { DE FORMACIÓN } \\
\text { DEPORTIVA" Colegio Pablo } \\
\text { de Tarso IED }\end{array}$ & $\begin{array}{l}\text { Contribuir al uso adecuado del tiempo libre de los } \\
\text { estudiantes, fomentando la practica en diferentes } \\
\text { disciplinas deportivas, que brinden experiencias } \\
\text { significativas que ayuden al desarrollo integral del } \\
\text { estudiante. }\end{array}$ & $\begin{array}{l}\text { 1. Contribuir al uso adecuado del tiempo libre de } \\
\text { los estudiantes del colegio Pablo de Tarso. } \\
\text { 2. Fomentar la practica deportiva, como estrategia } \\
\text { de desarrollo integral del estudiante. } \\
\text { 3. Fortalecer los procesos de desarrollo motor de } \\
\text { los y las estudiantes. }\end{array}$ & $\begin{array}{l}\text { El proyecto esta justificado por dos aspectos principalmente: } \\
\text { 1. La problemática social que se vive en la localidad, la cual } \\
\text { a influye de manera negativa en los niños y jóvenes, siendo } \\
\text { pertinente la búsqueda de estrategias para ocupar su tiempo } \\
\text { libre. } \\
\text { 2. La preocupación por el sedentarismo que cada vez } \\
\text { demuestran mas la población juvenil, bien sea por las } \\
\text { condiciones de vida de las familias o por el acercamiento de } \\
\text { los medios tecnológicos. }\end{array}$ & No presenta & $\begin{array}{l}\text { Se encuentra dentro del marco de } \\
\text { proyectos transversales que en la } \\
\text { institución educativa existen, } \\
\text { unculado al área de educación } \\
\text { fisica, recreación y deporte. }\end{array}$ & $\begin{array}{l}\text { Este proyecto esta dirigido a los } \\
\text { niños, niñas y adolescentes de la } \\
\text { localidad entre los } 6 \text { y los } 18 \text { años; } \\
\text { ya que para muchos de ellos que } \\
\text { poseen las cualidades físicas para } \\
\text { el desempeño deportivo les es } \\
\text { imposible demostrarlas debido a } \\
\text { las carencias de los recursos } \\
\text { económicos para inscribirse a las } \\
\text { Escuelas de Formación Deportiva } \\
\text { de carácter privado; mucho menos } \\
\text { participar en las ligas deportivas } \\
\text { ya que todas quedan fuera de } \\
\text { nuestra localidad e implica costos } \\
\text { de transporte. }\end{array}$ \\
\hline
\end{tabular}




\begin{tabular}{|c|c|c|c|c|c|c|}
\hline $\begin{array}{c}\text { PROVECTO } \\
\text { Pornada complementaria } \\
\text { 40x40 Secretaria de } \\
\text { Educación Bogotá }\end{array}$ & $\begin{array}{l}\text { Se presenta de manera implicita dentro del marco } \\
\text { té́rico del capitulo } 3 \text { dela siguiente manera: } \\
\text { "Desde esta administración se } \\
\text { espera ir más allá garantizándoles a los } \\
\text { niños, niñas y jóvenes la posibilidad de } \\
\text { potenciar un capital simbólico y cultural que les } \\
\text { permita ejercer el disfrute pleno de su } \\
\text { existencia en actividades lúdicas, recreativas y } \\
\text { artísticas, entre otras, que les posibilite } \\
\text { construirse como subjetividades capaces de } \\
\text { sentir, pensar y actuar libremente desde el } \\
\text { desarrollo de todas las dimensiones de su ser". }\end{array}$ & $\begin{array}{l}\text { Se presentan objetivos específicos para el logro } \\
\text { del general inmersos en el documento de la } \\
\text { siguiente manera: } \\
\text { 1. Se hace necesario generar ambientes de } \\
\text { aprendizaje adecuados en los espacios } \\
\text { institucionales, y también donde la ciudad se } \\
\text { presente como un escenario significativo } \\
\text { 2. Lograr la cualificación docente desde otras } \\
\text { lógicas y perspectivas pedagógicas mas acordes } \\
\text { con las demandas de las necesidades en interés } \\
\text { de los niños, niñas y jóvenes } \\
\text { 3. Garantizar la ampliación de tiempos escolares } \\
\text { 4. Mejorar y dotar el habitad escolar } \\
\text { 5.Garantizar la moulildad y la alimentación dentro } \\
\text { del entogue del cuidado integral. }\end{array}$ & $\begin{array}{l}\text { El documento no tiene un apartado explicito sin embargo } \\
\text { referencia que: } \quad \text { Es una propuesta que } \\
\text { responde a una politica nacional de jornada extendida, la } \\
\text { cual propone el diseño y e implementación de centros de } \\
\text { interes, orientados al desarrollo de capacidades artísticas, } \\
\text { deportivas y de expresión, buscando resignificar la ciudad y } \\
\text { la escuela como escenarios que aporten a la formación } \\
\text { alternativa del sujeto. }\end{array}$ & \begin{tabular}{|l|} 
El documento plantea el uso de la \\
investigación acción-participación \\
(IAP) y la reflexión accion- \\
participacion (RAP), como la ruta \\
metodolóogica de implementación \\
para la creación y ejecución de los \\
centros de interés, con el diseño \\
de unas secuencias didácticas \\
que responden a un proyecto \\
pedagógico para el cumplimiento \\
de los objetivos de aprendizaje que \\
genera la propuesta.
\end{tabular} & $\begin{array}{l}\text { El proyecto busca potenciar el } \\
\text { desarrollo de los ejes de } \\
\text { formación planteados en el PEI, } \\
\text { queriendo ser parte de los } \\
\text { procesos curriculares habituales } \\
\text { en diferentes áreas de } \\
\text { conocimiento a partir de la } \\
\text { creación de centros de interés } \\
\text { enfocados a la comunicación arte } \\
\text { y expresión, cienciai y tecnología } \\
\text { y gestión empresarial. }\end{array}$ & $\begin{array}{l}\text { El proyecto va dirigido a la } \\
\text { población escolar, de básica } \\
\text { primaria y básica secundaria, } \\
\text { orreciendo diversos centros de } \\
\text { interés optativos dentro y fuera de } \\
\text { las instalaciones del plantel } \\
\text { educativo, con el apoyo de } \\
\text { entidades externas como el } \\
\text { I.D.R.D, COMPENSAR, IDARTES. }\end{array}$ \\
\hline $\begin{array}{l}\text { PROYECTO Plan de } \\
\text { intervenciones colectivas } \\
\text { 2016. Espacio Educativo } \\
\text { Secretaria Distrital de Salud }\end{array}$ & $\begin{array}{l}\text { Promover el desarrollo integral de niños, niñas, } \\
\text { adolescentes y jóvenes, a través de la } \\
\text { implementación de estrategias de transformación } \\
\text { cultural, para la generación de entornos } \\
\text { saludables, desde las competencias del sector } \\
\text { salud. }\end{array}$ & $\begin{array}{l}\text { 1. Implementar acciones de promoción de la } \\
\text { salud, con la comunidad educativa, que permitan } \\
\text { transtormaciones de significados y prácticas, para } \\
\text { favorecer las condiciones de calidad de vida y } \\
\text { salud de niños, niñas, adolescentes y jóvenes } \\
\text { 2. Facilitar estrategias de trabajo sectorial, } \\
\text { intersectorial, social y comunitaria que favorezcan } \\
\text { la respuesta a las situaciones y condiciones } \\
\text { particulares de los actores del espacio educativo. }\end{array}$ & 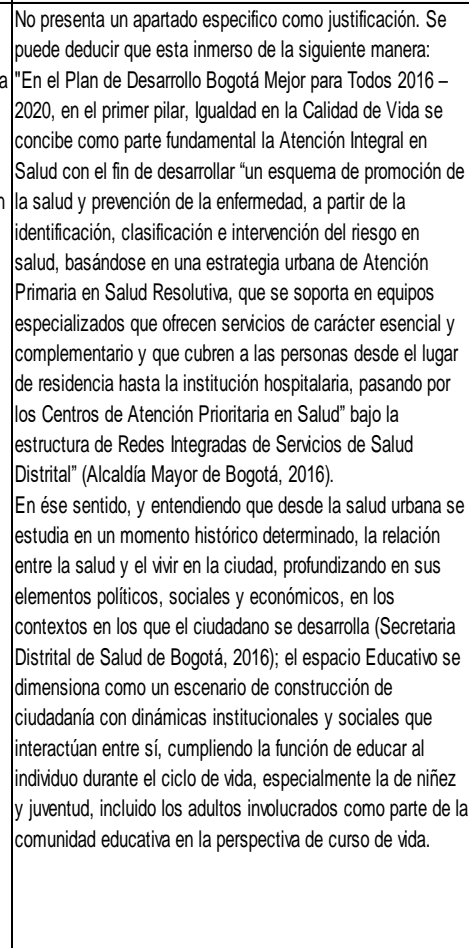 & \begin{tabular}{|l|} 
La propuesta metodológica \\
responde a la implementación del \\
proyecto "SINTONIZARTE" en la \\
modalidad de educación inicial \\
responde a las \\
Necesidades de las comunidades \\
educativas y propende por la \\
construcción de \\
espacios favorables para la salud, \\
a través de la comprensión y el \\
reconocimiento \\
de los recursos, habilidades y \\
potencialidades de docentes, \\
madries comunitarias y \\
familias. SINTONZARTE, en la \\
modalidad educación pre escolar, \\
básica y media, busca \\
responder a las necesidades de \\
las comunidades educativas en lo \\
competente al \\
sector salud; es una acción \\
integrada que gira alrededor del \\
arte, con el desarrollo \\
de una estrategia pedagógica \\
basada en el empleo de las \\
tecnologías de la \\
anformación y comunicación en \\
medios masivos, que facilite la \\
trasmisión de \\
mensajes claves pensados en una \\
lógica conversacional moderna. \\
\end{tabular} & $\begin{array}{l}\text { Para este componente el } \\
\text { documento señala elementos de } \\
\text { direccionamiento para la } \\
\text { comunidad educativa, para que } \\
\text { sean integrados pedagógicamente } \\
\text { en las instituciones, expresado de } \\
\text { la siguiente manera: } \\
\text { a. Las interacciones que se } \\
\text { generan entre los espacios, están } \\
\text { mediadas por un interés común: } \\
\text { el bienestar del niño/niña, } \\
\text { adolescente jóvévenes en general, } \\
\text { quienes construyen pautas } \\
\text { interacciónales que posibilitan la } \\
\text { emergencia de límites, normas, } \\
\text { códigos o patrones de conducta } \\
\text { que dan sentido a la vida; por } \\
\text { supuesto, dichos sistemas son } \\
\text { dinámicos, se van trastormando a } \\
\text { lo largo del curso de vida y su } \\
\text { intervención también irradia al } \\
\text { espacio Vivienda. } \\
\text { b. el espacio educativo propende } \\
\text { por realizar acciones que afecten } \\
\text { positivamente los determinantes } \\
\text { sociales y promuevan la salud y la } \\
\text { calidad de vida de la comunidad } \\
\text { educativa }\end{array}$ & $\begin{array}{l}\text { Se proponen estrategias de } \\
\text { promoción y prevención a través } \\
\text { del proceso de Gobernabilidad } \\
\text { para el mejoramiento de los } \\
\text { entornos se empleará las acciones } \\
\text { de participación activa en la } \\
\text { gestión intersectorial, social y } \\
\text { comunitaria que favorezca los } \\
\text { entornos escolares y de cuidado } \\
\text { de los niños, niñas, adolescentes } \\
\text { y jovvenes a nivel distrital/l/local para } \\
\text { identificar y y fortalecer la } \\
\text { corresponsabilidad en su } \\
\text { desarrollo integral, relacionado con } \\
\text { el entorno social, natural y } \\
\text { construido. } \\
\end{array}$ \\
\hline
\end{tabular}




\begin{tabular}{|c|c|c|c|c|c|c|}
\hline $\begin{array}{c}\text { PROYECTO } \\
\text { "AL COLEGIO EN BICl" }\end{array}$ & $\begin{array}{l}\text { Desarrollar un proceso pedagógico que potencie } \\
\text { una ciudadanía activa desde la promoción y el } \\
\text { uso cotidiano de la Bicicleta en los colegios } \\
\text { distritales la ciudad de Bogotá. }\end{array}$ & $\begin{array}{l}\text { 1. Generar actividades pedagógicas que } \\
\text { desarrollen a través de l ládica las capacidades } \\
\text { ciuddadanas, mientras el estudiante afianza su } \\
\text { relación con la bicicleta y su entomo. } \\
\text { 2.Propiciar acciones que concienticen y } \\
\text { promuevan el desplazamiento en bicicleteta de los } \\
\text { escolares bogotanos. } \\
\text { 3. Impulsar la integración del entorno escolar con } \\
\text { las comunidades para mejorar la apropiación y } \\
\text { disfrute del espacio público, así como su } \\
\text { transformación. } \\
\text { 4.Promover la protección, conivivencia y seguridad } \\
\text { de los niños y niñasas y de sus comunidades. } \\
\text { 5. Incorporar un entoque diferencial y de } \\
\text { perspectiva de género, que potencie la } \\
\text { participación de las niñas en el proyecto. } \\
\text { 6.Fomentar la actividad fisica y el uso de la } \\
\text { bicicleta como hábito de vida saludable. } \\
\end{array}$ & 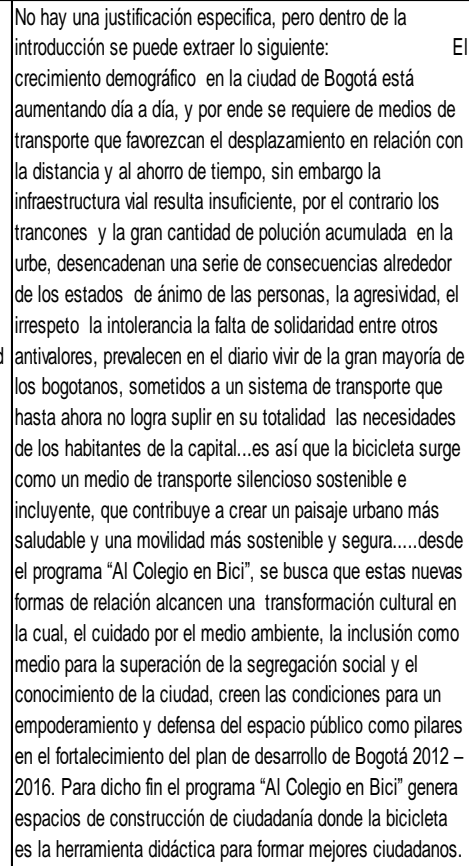 & 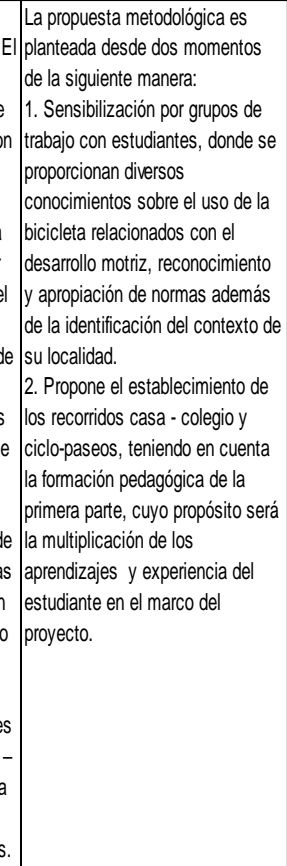 & \begin{tabular}{|l|} 
En el P:E.l institucional se \\
propone la formación de \\
ciudadanas, que fomentan valores \\
en aras de la construcción de \\
proyectos de vida productivos, por \\
lo tanto el reconocimiento del \\
contexto local, asi como de sus \\
normas fomenta una apropiación \\
de los espacios y por ende su \\
cuidado, lo que se reflejajá en el \\
e mejoramiento de la calidad de \\
vida, la seguridad ciuddadana y el \\
conocimiento de las normas en la la \\
via.
\end{tabular} & $\begin{array}{l}\text { El proyecto propone dos aristas. } \\
\text { Por un lado un mejoramiento de la } \\
\text { convivencia ciudadana a partir del } \\
\text { reconocimiento de la norma y el } \\
\text { territorio, en la búsqueda de una } \\
\text { apropiación y un respeto los } \\
\text { bienes públicos. } \\
\text { Por otra parte aporta } \\
\text { significativamente a la política } \\
\text { ambiental, haciendo conciencia en } \\
\text { el uso de la bicicleta como medio } \\
\text { de transporte impactando } \\
\text { positivamente en los hábitos de } \\
\text { las personas para el mejoramiento } \\
\text { de la salud y del ambiente de la } \\
\text { ciudad. }\end{array}$ \\
\hline
\end{tabular}




\begin{tabular}{|c|c|c|c|c|c|c|c|}
\hline \multicolumn{8}{|c|}{ MATRIZ 2. ANALISIS DE DOCUMENTOS } \\
\hline & \multicolumn{7}{|c|}{$\begin{array}{l}\text { UNIDADES DE ANALISIS } \\
\end{array}$} \\
\hline $\begin{array}{l}\text { DOCUMENTO DE } \\
\text { ANALISIS }\end{array}$ & $\begin{array}{l}\text { IDENTIFICACION } \\
\text { DEL DOCUMENTO }\end{array}$ & $\begin{array}{c}\text { TIPOY } \\
\text { CLASIFICACION } \\
\text { DEL DOCUMENTO }\end{array}$ & $\begin{array}{l}\text { ENFOQUE } \\
\text { PEDAGOGICO }\end{array}$ & $\begin{array}{l}\text { CONCEPTO DE } \\
\text { EDUCACION FISICA }\end{array}$ & $\begin{array}{c}\text { CONCEPTOS Y CONTENIDOS SOBRE ESTILOS } \\
\text { DE VIDA SALUDABLES }\end{array}$ & $\begin{array}{l}\text { ASPECTOS VINCULARES ACERCA DE LA } \\
\text { PROMOCION Y PREVENCION EN SALUD }\end{array}$ & $\begin{array}{l}\text { ASPECTOS VINCULARES CON } \\
\text { OTROS DOCUMENTOS }\end{array}$ \\
\hline $\begin{array}{l}\text { Plan de Área } \\
\text { Colegio Pablo de } \\
\text { Tarso IED }\end{array}$ & \begin{tabular}{|l} 
Plan de área Campo \\
de pensamiento Ed. \\
Física y deportes. \\
Jaime Acosta, Ever \\
williams, Edwin \\
González, Raúl Pinzón. \\
(2016). Colegio Pablo \\
de Tarso IED. \\
Documento \\
Institucional.
\end{tabular} & \begin{tabular}{|l} 
Documento \\
conceptual, \\
compuesto por la \\
planeación de \\
asignatura y la \\
malla curricular
\end{tabular} & \begin{tabular}{|l|} 
No presenta un enfoque \\
explicito, la propuesta \\
curricular da cuenta del \\
desarrollo de una \\
propuesta pedagógica \\
integral humanista
\end{tabular} & \begin{tabular}{|l|} 
Corresponde en gran \\
parte a la \\
conceptualización \\
definida desde lo \\
normativo, respondiendo \\
a los lineamientos \\
curriculares establecidos \\
para el área de ed. Física. \\
Se evidencia una \\
formulación conceptual \\
diferencial para Media en \\
cuanto a la \\
implementación de \\
nuevas estrategias de la \\
enseñanza de la Ed. física.
\end{tabular} & \begin{tabular}{|l|} 
El documento no precisa contenidos explíititos \\
acerca de hábitos de vida saludable; para el ciclo \\
Vintegra practicas que responden a una \\
apropiación general de la actividad física para el \\
cuidado del cuerpo.
\end{tabular} & $\begin{array}{l}\text { El documento no presenta ningún tipo de } \\
\text { estrategia en relación a la prevención y } \\
\text { promoción en salud. }\end{array}$ & $\begin{array}{l}\text { El documento responde a elementos } \\
\text { direccionados por los lineamientos } \\
\text { en el área de Educación Fisica en } \\
\text { cuanto a temas y contenidos, según } \\
\text { grado y nivel escolar especifico. Así } \\
\text { mismo se ve evidenciado en el ultimo } \\
\text { ciclo de formación la relación de } \\
\text { contenido con el propósito del P.E.I. } \\
\text { "Construcción de Proyectos de Vida } \\
\text { Productivos" a través de la } \\
\text { formulacion, diseño y la aplicación } \\
\text { de diferentes propuestas en actividad } \\
\text { física. }\end{array}$ \\
\hline $\begin{array}{c}\text { Proyecto } \\
\text { "ESCUELAS DE } \\
\text { FORMACIÓN } \\
\text { DEPORTIVA" } \\
\text { Colegio Pablo de } \\
\text { Tarso IED }\end{array}$ & \begin{tabular}{|l|} 
Proyecto de \\
escuelas de \\
formación \\
deportivas. Autores \\
Lic. Ever Williams y \\
Lic. Wilson Gómez \\
(2014). Colegio \\
Pablo de Tarso IED. \\
Documento \\
Institucional.
\end{tabular} & $\begin{array}{l}\text { Documento } \\
\text { conceptual, } \\
\text { compuesto por } \\
\text { una introducción, } \\
\text { objetivos, marco } \\
\text { de referencia } \\
\text { legal, marco } \\
\text { institucional, } \\
\text { referencia } \\
\text { histórica y } \\
\text { organización del } \\
\text { proyecto. }\end{array}$ & \begin{tabular}{|l|} 
No presenta un \\
enfoque explicito, la \\
propuesta se enfatiza \\
en responder a las \\
necesidades de una \\
parte de la población \\
del contexto escolar, \\
desde el ámbito \\
deportivo netamente
\end{tabular} & \begin{tabular}{|l|} 
No hay una \\
conceptualización que \\
se acerque a los fines \\
de la educación física, \\
se trabaja desde \\
conceptos como \\
Tiempo libre, \\
Recreación y educación \\
extra- escolar, \\
direccionando todos \\
los procesos hacia el \\
deporte y las \\
competencias \\
deportivas.
\end{tabular} & \begin{tabular}{|l|} 
El documento no precisa contenidos \\
explíitos acerca de hábitos de vida \\
saludable; desde la justificación trata de \\
evidenciar el problema del sedentarismo de \\
una manera muy superficial sin ninguna clase \\
de conceptualización o referencia mas \\
amplia, plasmando la influencia que las \\
nuevas tendencias tecnológicas tienen en \\
los jóvenes y queriendo brindar una \\
oportunidad de realizar actividades \\
deportivas en el tiempo libre, que sean mas \\
útiles para mejorar su calidad de vida.
\end{tabular} & $\begin{array}{l}\text { El documento no presenta ningún tipo de } \\
\text { estrategia en relación a la prevención y } \\
\text { promoción en salud. } \\
\end{array}$ & $\begin{array}{l}\text { El documento responde a } \\
\text { direccionamientos, leyes y } \\
\text { artículos reflejados en la } \\
\text { constitución política de Colombia, } \\
\text { La ley general de educación (ley } \\
\text { 115/94), Ley general del deporte } \\
\text { (ley 181/95), Ley General de la } \\
\text { Juventud (Ley 375/97) y el manual } \\
\text { de convivencia del colegio Pablo } \\
\text { de tarso I.E.D. }\end{array}$ \\
\hline
\end{tabular}




\begin{tabular}{|c|c|c|c|c|c|c|c|}
\hline $\begin{array}{l}\text { Proyecto "jornada } \\
\text { completa" } \\
\text { Orientaciones del } \\
\text { Área Integradora de } \\
\text { Ed. Física, } \\
\text { recreación y } \\
\text { deportes para la } \\
\text { implementación de } \\
\text { la jornada completa. }\end{array}$ & $\begin{array}{l}\text { Este documento le } \\
\text { pertenece a la } \\
\text { Secretaria de } \\
\text { Educación del } \\
\text { Distrito. Autores } \\
\text { Nidia Torres, Pedro } \\
\text { Galvis, Nelly } \\
\text { Adriana Penagos. } \\
\text { (Octubre 2015). } \\
\text { Documento } \\
\text { distrital. } \\
\end{array}$ & $\begin{array}{l}\text { Documento } \\
\text { normativo - } \\
\text { conceptual } \\
\text { compuesto de } \\
\text { presentación, } 2 \\
\text { capítulos } \\
\text { conceptuales y } \\
\text { bibliografía }\end{array}$ & $\begin{array}{l}\text { El enfoque que plantea } \\
\text { el documento es de } \\
\text { carácter humanista, al } \\
\text { establecer la relación } \\
\text { permanente medio, } \\
\text { conciencia, } \\
\text { movimiento para la } \\
\text { formación del sujeto. } \\
\text { Propende la } \\
\text { vinculación del } \\
\text { objetivo principal de la } \\
\text { Ed. Física con los } \\
\text { aprendizajes } \\
\text { esenciales para el } \\
\text { buen vivir (Aprender a } \\
\text { ser, aprender a vivir } \\
\text { juntos, aprender a } \\
\text { hacer y aprender a } \\
\text { conocer. }\end{array}$ & $\begin{array}{l}\text { Se define como una } \\
\text { practica y una derecho } \\
\text { social, generando } \\
\text { aprendizajes } \\
\text { esenciales que les } \\
\text { permitan a los niños, } \\
\text { niñas y jóvenes } \\
\text { reconocerse y } \\
\text { relacionarse con los } \\
\text { otros, construyéndose } \\
\text { como sujetos sociales. }\end{array}$ & $\begin{array}{l}\text { Los conceptos están construidos a partir de la } \\
\text { categoría de aprendizaje esencial } \\
\text { manifestados en la justificación de la } \\
\text { creación y desarrollo de centros de interés a } \\
\text { partir de la formulación de un sujeto } \\
\text { multidimensional, en el cual sus condiciones } \\
\text { fisicas, emocionales, psicomotrices, } \\
\text { estéticas, comunicativas, socioculturales } \\
\text { sean formadas y plasmadas atraves de lo } \\
\text { corporal. A través de el fortalecimiento de } \\
\text { hábitos saludables en mente y cuerpo. }\end{array}$ & $\begin{array}{l}\text { Se plantean los aprendizajes esenciales } \\
\text { por ciclos, así: Ciclo I EXPLORACION DEL } \\
\text { CUERPO: El niño reconoce y explora su } \\
\text { cuerpo, así como la necesidad del } \\
\text { autocuidado desde la higiene, } \\
\text { comunicación de emociones y la actividad } \\
\text { física. } \\
\text { Ciclo II EXPRESION CORPORAL: } \\
\text { Identificación de su desarrollo motor a } \\
\text { traves de la actividad física y el juego } \\
\text { entendidos como practicas saludables. } \\
\text { Ciclo III EXPRESION DE EMOCIONES: Pro } \\
\text { pendiente a identificación de emociones y } \\
\text { resolución de las mismas en contexto } \\
\text { como un factor de calidad de vida. } \\
\text { Ciclo IV DESARROLLO cORPORAL: Es la } \\
\text { apropiación y desarrollo de los } \\
\text { aprendizajes alcanzados en los ciclos } \\
\text { anteriores manifestados a partir de las } \\
\text { practicas que se desarrollan desde lo } \\
\text { corporal priorizando en la conservación de }\end{array}$ & $\begin{array}{l}\text { La formulación conceptual y } \\
\text { normativa del documento } \\
\text { referencia en su elaboración } \\
\text { textos como: } \\
\text {-Plan decenal del deporte, la } \\
\text { recreación, la educación física y la } \\
\text { actividad física para el desarrollo } \\
\text { humano la convivencia y la paz } \\
2009 \text {-2019 (instituto colombiano } \\
\text { del deporte COLDEPORTES). } \\
\text {-Lineamentos curriculares en } \\
\text { Educación Física, recreación y } \\
\text { deporte (MEN). } \\
\text {-Orientaciones pedagógicas para } \\
\text { la Educación Física, Recreación y } \\
\text { Deporte (Doc. \# 15) SED 2010. } \\
\text {-Carta Internacional de la } \\
\text { Educación Física, recreación y } \\
\text { deporte (1978) Organización de } \\
\text { las naciones unidas para la } \\
\text { educación, ciencia y la cultura. }\end{array}$ \\
\hline $\begin{array}{c}\text { Plan de } \\
\text { intervenciones } \\
\text { colectivas } 2016 . \\
\text { Espacio Educativo } \\
\text { Secretaria Distrital } \\
\text { de Salud }\end{array}$ & $\begin{array}{l}\text { Plan de } \\
\text { intervenciones } \\
\text { colectivas 2016, } \\
\text { perteneciente a la } \\
\text { secretaria distrital } \\
\text { de salud (vigencia } \\
\text { 2016-2017). Aportes } \\
\text { técnicos espacio } \\
\text { educativo. }\end{array}$ & $\begin{array}{l}\text { Documento de } \\
\text { carácter } \\
\text { normativo con } \\
\text { referentes } \\
\text { teóricos } \\
\text { genéricos sin } \\
\text { profundidad. } \\
\text { Aparte } \\
\text { Técnico espacio } \\
\text { educativo. } \\
\text { Componente } \\
\text { conceptual, } \\
\text { referente } \\
\text { metodológico y } \\
\text { marco operativo. }\end{array}$ & $\begin{array}{l}\text { Muestra una propuesta } \\
\text { de promoción redes de } \\
\text { servicios sectoriales en } \\
\text { salud general para la } \\
\text { comunidad educativa. }\end{array}$ & $\begin{array}{l}\text { Muestra una propuesta } \\
\text { de promoción redes de } \\
\text { servicios sectoriales en } \\
\text { salud general para la } \\
\text { comunidad educativa. }\end{array}$ & $\begin{array}{l}\text { El documento no esboza un concepto ni } \\
\text { teoría particular de hábitos de vida } \\
\text { saludable, plantea dentro de las metas del } \\
\text { programa SINTONIZARTE estrategias y } \\
\text { acciones para la promoción de hábitos de } \\
\text { vida saludable relacionadas hacia la } \\
\text { detección temprana de las enfermedades } \\
\text { crónicas no transmisibles. }\end{array}$ & $\begin{array}{l}\text { Se presentan unos determinantes sociales } \\
\text { de carácter estructural, intermedio y } \\
\text { proximales; como espacios de } \\
\text { intervención y transformación cultural, } \\
\text { donde se pretende promover estrategias } \\
\text { para la materialización de políticas } \\
\text { públicas conducentes al mantenimiento } \\
\text { de la salud y el mejoramiento de la calidad } \\
\text { de vida. }\end{array}$ & $\begin{array}{l}\text { Refiere a una articulación y } \\
\text { fundamentación con base a: } \\
\text { - Plan de desarrollo distrital. } \\
\text { Bogotá 2016-2020. Alcaldía mayor } \\
\text { de Bogotá. } \\
\text { - Resolución 518 Secretaria } \\
\text { Distrital de Salud de Bogotá. }\end{array}$ \\
\hline
\end{tabular}




\begin{tabular}{|c|c|c|c|c|c|c|c|}
\hline $\begin{array}{c}\text { PROYECTO } \\
\text { "AL COLEGIO EN } \\
\text { BICl" }\end{array}$ & $\begin{array}{l}\text { Proyecto "PEDALEA } \\
\text { POR BOGOTA" y "AL } \\
\text { COLEGIO EN BICI" } \\
\text { Instituto Distrital } \\
\text { Para La Recreación } \\
\text { y El Deporte. } \\
\text { Jorge Mauricio } \\
\text { Ramos Martínez } \\
\text { Coordinador } \\
\text { Pedalea por Bogotá } \\
\text { Fabio Andrés } \\
\text { Navarrete Riaño } \\
\text { Monitor al colegio } \\
\text { en Bici } \\
\text { Febrero } 2014\end{array}$ & $\begin{array}{l}\mathrm{L} \\
\text { bocumento de } \\
\text { carácter } \\
\text { normativo con } \\
\text { tiene } \\
\text { Componente } \\
\text { conceptual, } \\
\text { marco } \\
\text { pedagógico, } \\
\text { referente } \\
\text { metodológico y } \\
\text { marco operativo. }\end{array}$ & \begin{tabular}{|l} 
Muestra un método \\
pedagógico \\
experimental con el \\
cual se pretende \\
generar aprendizajes \\
significativos en torno \\
al descubrimiento \\
guiado y la solución de \\
problemas, con \\
sesiones dinámicas \\
que invitan a la \\
participación y la \\
reflexión, teniendo en \\
cuenta su contexto \\
social y cultural.
\end{tabular} & $\begin{array}{l}\text { Muestra un aporte } \\
\text { donde se involucran } \\
\text { todos los aspectos del } \\
\text { desarrollo motriz } \\
\text { cognitivo y social, que } \\
\text { serán estimulados } \\
\text { desde juegos lúdicos } \\
\text { en cada encuentro con } \\
\text { los estudiantes, estos } \\
\text { darán un valor } \\
\text { agregado a su } \\
\text { desarrollo físico. }\end{array}$ & $\begin{array}{l}\text { El documento hace referencia a la aprensión } \\
\text { de hábitos de vida saludable de la siguiente } \\
\text { manera: "Las capacidades físicas como los } \\
\text { son: la fuerza, velocidad, flexibilidad, } \\
\text { coordinación, resistencia serán fortalecidas } \\
\text { desde un ámbito recreativo que pretende } \\
\text { promover en el estudiante la apropiación de } \\
\text { estilos de vida saludable, reconociendo la } \\
\text { importancia de la actividad física." }\end{array}$ & $\begin{array}{l}\text { Se reconoce en el documento las } \\
\text { propuestas en prevención y salud } \\
\text { manifestadas desde estamentos } \\
\text { internacionales, plasmándolas } \\
\text { textualmente de la siguiente manera: } \\
\text { "Teniendo en cuenta que la Organización } \\
\text { Mundial de la Salud (OMS) resalta la } \\
\text { actividad física como una herramienta que } \\
\text { contribuye a la prevención del sobrepeso y } \\
\text { la obesidad como otras enfermedades no } \\
\text { transmisibles asociadas, el IDRD a través } \\
\text { del programa "al colegio en bici" } \\
\text { promueve y facilita el acceso a los } \\
\text { estudiantes a la estimulación y practica de } \\
\text { actividad física".... }\end{array}$ & $\begin{array}{l}\text { PECC, SED. 2012 (Proyecto educativo } \\
\text { para la ciudadaní y la convivencia) } \\
\text { Plan de desarrollo 2012-2016 Plan } \\
\text { de desarrollo económico y social y de } \\
\text { obras públicas para Bogotá Distrito } \\
\text { Capital 2012-2016. } \\
\\
\end{array}$ \\
\hline
\end{tabular}

